\title{
Vinyl/furo-indoles and gold catalysis: new achievements and future perspectives for the synthesis of complex indole derivatives
}

Valentina Pirovano, ${ }^{[a]}$ Giorgio Abbiati, ${ }^{[a]}$ Elisa Brambilla, ${ }^{[a]}$ and Elisabetta Rossi*[a]

Abstract: The reactivity of vinyl/furo-indole derivatives with gold-activated $\pi$-systems is the subject of extensive investigation. In the presence of these electrophilic partners, the realised transformations allow for the construction of different and fascinating architectures via cycloaddition and cyclisation reactions often included in cascade processes. The reactions realised involving in these processes an external substituent at the indole moiety are the subject of the present minireview.

\section{Introduction}

Indoles met gold catalysis in the early 2000s when the first reports on the inter and intramolecular gold(I) and gold(III) catalysed functionalization of indoles with alkynes, allenes and alkenes appeared in the literature. ${ }^{[1]}$ Thus, the activation of these $\pi$-systems by gold catalysts furnishes the "ideal" electrophilic partners for the electronrich indole heterocycle. In the following years, this apparently simple reaction scheme has been extended to more complex indoles and challenging unsaturated systems allowing for the synthesis of polycyclic or highly substituted indole derivatives. The reported methodologies involve either cyclization and cycloaddition reactions or cascade and multicomponent reactions. ${ }^{[2]}$ In scheme 1, we exemplify the general reaction pathways involving indoles and goldactivated $\pi$-systems. Therefore, the cyclization processes can involve both $\mathrm{C} 2-\mathrm{C} 3$ double bond and N-C2 bond of the starting indoles, scheme 1a. Moreover, an external substituent can take part in these reactions allowing for the construction of different motifs, scheme $1 \mathrm{~b}$. It is worth to note that in both cases the primary cyclization compounds can evolve toward the formation of rearrangement products expanding the scope of these transformations via cascade processes. These latter can be also realised thru sequences involving simple functionalisation followed by rearrangement reactions, scheme 1c.

Starting from 2013, we have been actively involved in gold catalysed transformations of the type reported in scheme $1 \mathrm{~b}$, which are the topic of this minireview.

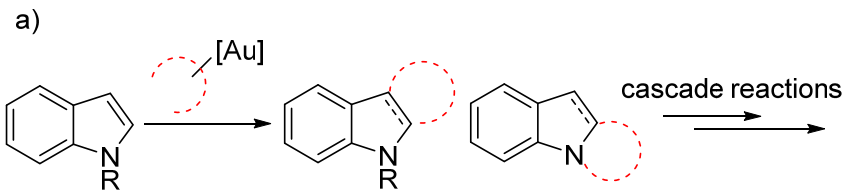

$$
R=P G, H
$$

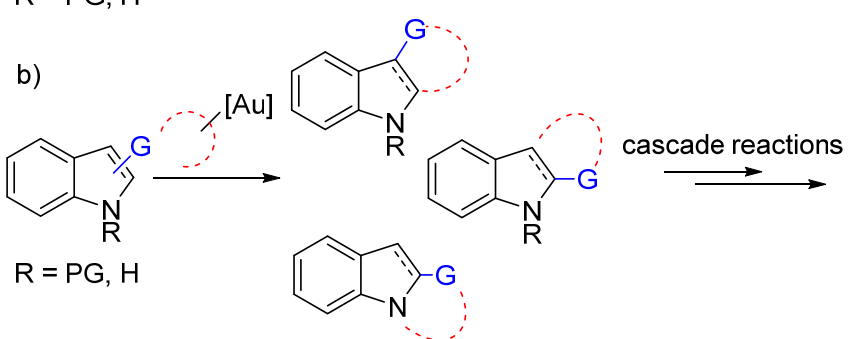<smiles>[R]c1cccc2c(C[Al]C)c[nH]c12</smiles>

Scheme 1. Gold-catalysed synthesis of polycyclic and complex indoles. 
For example, at the beginning of our investigation, we described the cycloaddition reactions of vinylindoles 1 with Lewis acids activated electron-poor alkenes, scheme $2 .{ }^{[3]}$ The reaction occurs in the presence of $\mathrm{BF}_{3}\left(\mathrm{OEt}_{2}\right)$ via a [4+2] cycloaddition followed by $1,3[\mathrm{H}]$-shift giving rise to the corresponding tetrahydrocarbazoles $\mathbf{3} / \mathbf{3}^{\prime}$ in good diastereoisomeric excesses. Then, for the same reactions, we compared the catalytic activity of gold salts and complexes to traditional Lewis acids. ${ }^{[3 c]}$ The best performing catalysts were gold(III) chloride and $\mathrm{Au}\left(\mathrm{PPh}_{3}\right) \mathrm{Cl} / \mathrm{AgOTf}$ giving rise to results in line with those obtained with the best performing Lewis acid catalysts. Moreover, although gold catalysts can act both as $\sigma_{-}{ }^{[4]}$ and $\pi$-philic activators, ${ }^{[5]}$ in all tested reactions the gold catalysts acted as an effective $\sigma$ philic Lewis acid able to activate the enone cycloaddition partner.
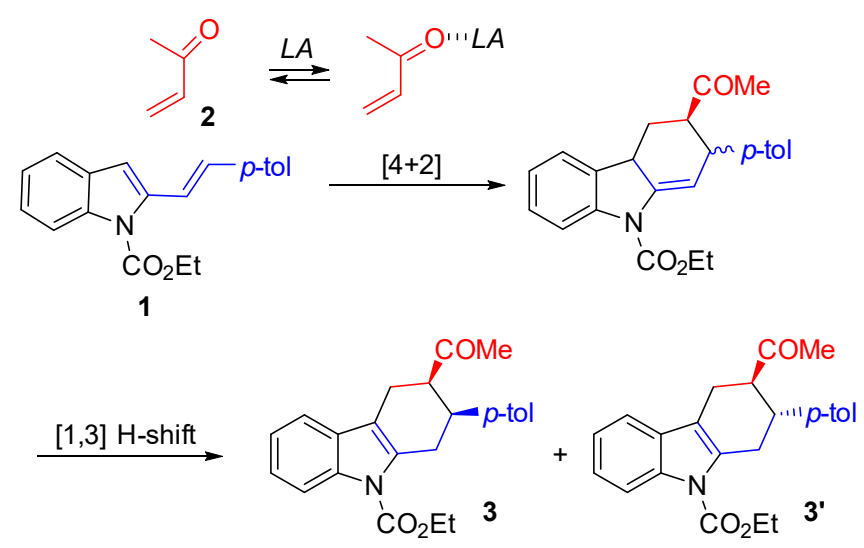

Reaction conditions

a) $\mathrm{BF}_{3}(\mathrm{OEt})_{2}(15 \mathrm{~mol} \%)$, toluene, $-20^{\circ} \mathrm{C}, 1.5 \mathrm{~h}$, yield $92 \%$, de $84 \%$

b) $\mathrm{AuCl}_{3}(2 \mathrm{~mol} \%)$, toluene, r.t., $1.5 \mathrm{~h}$, yield $99 \%$, de $85 \%$

c) $\mathrm{Au}\left(\mathrm{PPh}_{3}\right) \mathrm{Cl} / \mathrm{AgOTf}(2 \mathrm{~mol} \%)$, toluene, r.t., $24 \mathrm{~h}$, yield $96 \%$, de $86 \%$

Scheme 2. Lewis acid and gold catalysed cycloaddition reactions of 2-vinylindoles 1 with electron-poor alkenes 2.

Beside gold, also other coinage metals such as copper and silver are able to promote the cycloaddition reactions of vinylindoles with classical dienophiles (copper ${ }^{[6]}$ or unactivated $\pi$-systems (silver) ${ }^{[7]}$ Later on, we moved our attention to the [4+2] cycloaddition reactions of vinylindoles with gold activated $\pi$-systems. In particular, we exploited the reactivity of 2-vinyl and 3-vinylindoles (section 2 ) as well as $4 \mathrm{H}$-furo[3,2-b]indoles (section 3 ) with different unsaturated systems for the synthesis of polycyclic indoles as well as of complex indole derivatives.

In this minireview, we report the results obtained by us and by other research groups, active in the same or related research fields, on gold catalysed transformations of the type reported in scheme $1 \mathrm{~b}$. A final section (section 4) reports a critical survey of the obtained results and the possible and desirable expansions of this chemistry.

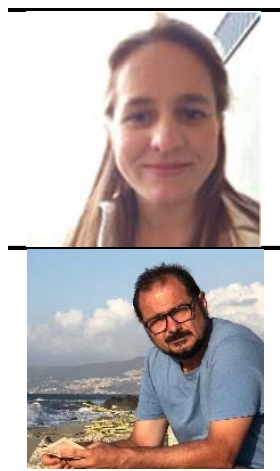

Valentina Pirovano was born in Bergamo (Italy) in 1986. In 2010, after a six-month stay in the research group of Prof. Lutz Ackerman (University of Göttingen), she obtained her master's degree in Pharmaceutical Chemistry and Technology at the University of Milan (Italy). From 2011 to 2014 she pursued a co-tutored Ph.D. under the supervision of Prof. Elisabetta Rossi (University of Milan) and Dr. Rubén Vicente (University of Oviedo, Spain). Since 2014, she has been working as a postdoctoral researcher in the group of Prof. Elisabetta Rossi, focusing her studies on transition-metal catalysis applied to the synthesis and the functionalization of heterocyclic moieties.

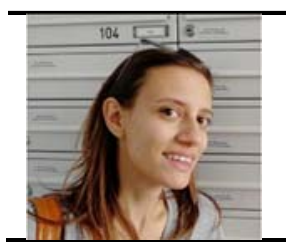

Giorgio Abbiati received the B.Sc. degree in Pharmaceutical Chemistry and Technology in 1997 and the Ph.D. in Pharmaceutical Sciences in 2000 from the University of Milan. In 2005, he was appointed Assistant Professor (Researcher) at the Department of Medicinal Chemistry of the University of Milan and became Associate Professor in 2015 . He is lecturer in Organic Chemistry and Environmental Chemistry at the University of Milan. His research is focused on the study of novel synthetic methodologies for the preparation and the functionalization of heterocyclic compounds. From a methodological point of view, main interest are devoted to homogenous metal catalysis (in particular Ag, but also $\mathrm{Cu}$, Au and Pd), domino and multicomponent approaches and MAOS (MicrowaveAssisted Organic Synthesis). The main topic is the study of synthetic potential of arylacetylenes bearing a proximate reactive group for the preparation of oxygen- and nitrogen-containing heterocycles, also in their polycyclic forms.

Elisa Brambilla was born in Monza (Italy) in 1993. In 2017, she obtained her master's degree in Pharmaceutical Chemistry and Technology at the University of Milan (Italy). Since 2017, she has been pursuing a Ph.D. under the supervision of Prof. Elisabetta Ross (University of Milan). Since 2019 she has been working as a PhD researcher in the laboratories of professor A. Stephen K. Hashmi (Heidelberg University), focusing her studies on functionalization of heterocyclic compound to synthetize complex derivatives under metal catalysis. 
Elisabetta Rossi received her master's degree in Pharmaceutical Chemistry and Technology in 1981 from the University of Milan. In 1984, she obtained a specialization qualification in Analytical and Chemical Methodologies for Fine Chemicals at the Politecnico of Milan. She is currently full professor at the Department of Pharmaceutical Sciences at the University of Milan. Her research activity is focused on the study of new synthetic methodologies for the synthesis and functionalization of heterocyclic compounds through domino and cascade approaches, intramolecular cyclization, and cycloaddition reactions catalysed by Lewis acids or transition metals (In, B, $\mathrm{Sc}, \mathrm{Ti}, \mathrm{Pd}, \mathrm{Au}$, and $\mathrm{Ag})$. 


\section{Reactivity of 2-vinyl and 3-vinylindoles with gold-activated allenes}

In our first investigation, we used 2-vinylindoles 1 as $4 \pi$-components in [4+2] cycloadditions with gold-activated allenes $4^{[8]}$ for the synthesis of 3-amidomethyliden-tetrahydrocarbazoles 5 , scheme 3. ${ }^{[9]}$

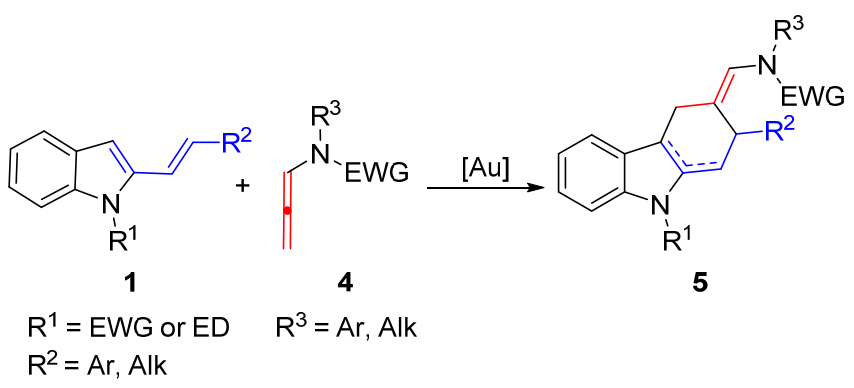

Scheme 3. [4+2] cycloaddition between 2-vinylindoles 1 and allenes 4 .

We became involved in the chemistry of 2-vinylindoles since 2006 when we published the synthesis of a new stable indolyl triflate $\mathbf{6}$, scheme 4. ${ }^{[10]}$

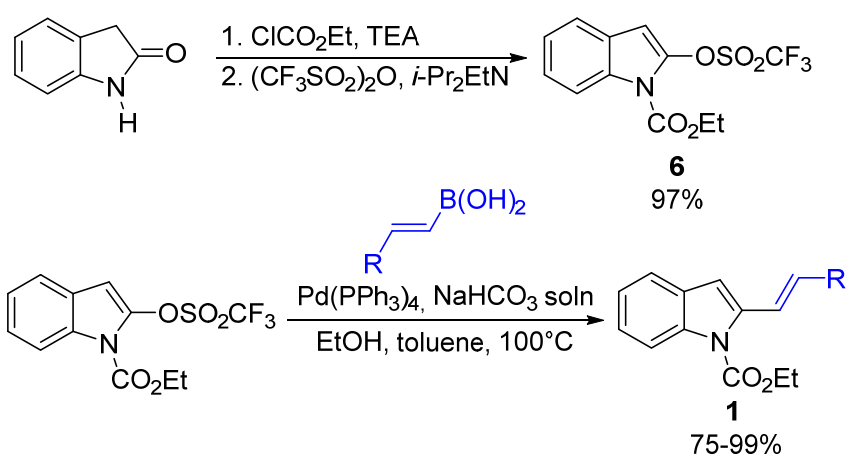

Scheme 4. Stereoselective synthesis of 2-vinylindoles 1.

Compound 6 can participate in palladium catalysed Suzuki-Miyaura reactions with vinylboronic acids for the stereospecific synthesis of $E$-2-vinylindoles 1 in good to excellent yields.

When $\pi$-systems and in particular dienes are involved as nucleophiles in the reactions with gold-activated allenes, the formation of a bond normally occurs at the external allene carbon and may be coupled with the creation of a second $\mathrm{C}$-C bond in a concerted or stepwise fashion resulting in formal $[4+2],[2+2]$ and $[4+3]^{[11]}$ cycloaddition products, scheme $5 .^{[12]}$

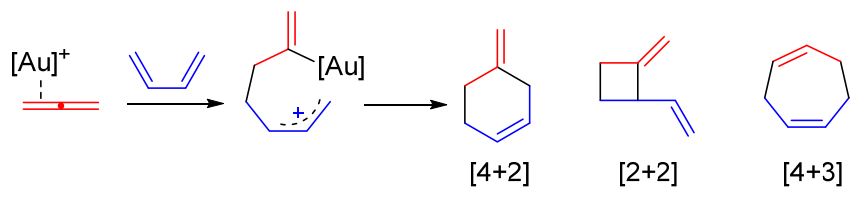

Scheme 5. Gold(I) activated allenes and dienes: plausible cycloaddition mode.

Thus, allenes can participate as C2 or C3 synthons in cycloaddition reactions. Initially, this kind of reactivity has been widely studied in intramolecular processes. ${ }^{[13]}$ Thereafter, in 2011, Goeke ${ }^{[14]}$ and Mascareñas ${ }^{[15]}$ independently described the first examples of the intermolecular cycloadditions between acyclic dienes $\mathbf{7}$ and, respectively, alkyl allenyl ethers $\mathbf{8}$ or allenamides (in this review the term "allenamide" refers to $\mathrm{N}-\mathrm{C}=\mathrm{O}$ substituted allenes) $\mathbf{4}$ for the synthesis of cyclohexene derivatives $\mathbf{9}$, scheme 6 . 


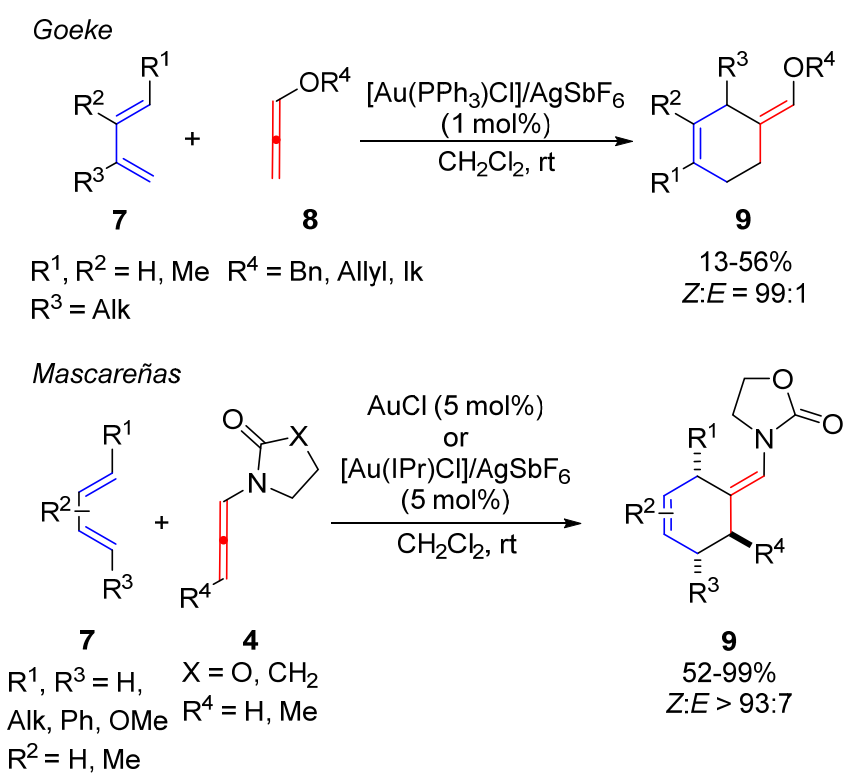

Scheme 6. Gold-catalysed [4+2] cycloaddition between acyclic dienes 7 and allenes 8 or 4 .

Alkyl allenyl ethers 8 and allenamides 4 were efficiently activated towards the cycloaddition with acyclic dienes by cationic gold(I) triphenylphosphane catalyst, $\left[\mathrm{Au}\left(\mathrm{Ph}_{3} \mathrm{P}\right)\left(\mathrm{SbF}_{6}\right)\right]$, or by simple $\mathrm{AuCl}$ leading to the corresponding cyclohexene derivatives 9. The reactions outcome strictly depend on the nature of the substrates employed. Reactions performed with allenyl ethers seem to be more challenging and the corresponding cyclohexenes were formed only in poor yields employing simple acyclic dienes and in moderate yields using more reactive acyclic dienes such as homo-myrcene. However, excellent results in terms of regio- and diastereoselection were obtained. The scarce chemical yields could be related to the inherent instability of allenyl ethers that decompose when prolonged reaction times are required. This statement finds a confirmation looking at the results obtained by the same authors in the reaction with cyclic dienes (cyclopentadienes and alkylcyclopentadienes). These more reactive substrates yield the corresponding cyclohexenes in good to excellent yields even if regio- and diastereoselections are lower. Meanwhile, using allenamides and acyclic dienes excellent results in term of yield, regio- and diastereoselectivity were achieved by Mascareñas, which reported also the only example on the use of a chiral disubstituted allenamide bearing a methyl group at the distal position. In both reactions, the proposed mechanism involves gold coordination at the external double bond of the allene moiety followed by the formation of the gold-allyl cation $I$, stabilized by the presence of the oxygen or the nitrogen atom, respectively, scheme 7.
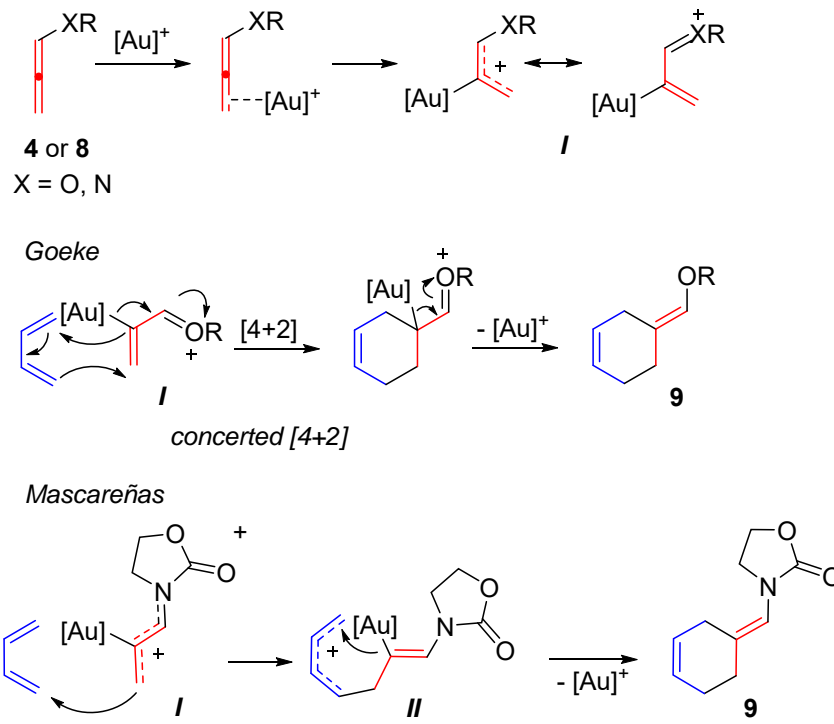

stepwise [4+2]

Scheme 7. Concerted or stepwise [4+2] cycloadditions involving stabilized gold-allyl cation $I$.

Intermediate $\boldsymbol{I}$ can then react with the diene in a concerted or stepwise fashion, giving rise to final cyclohexene derivatives after deauration. Theoretical calculation made by Goeke demonstrated the effectiveness of a concerted [4+2] mechanism for the reaction of 
allenyl ethers with both cyclic and linear dienes. Moreover, they demonstrated that the preferred $Z$ geometry at the exocyclic double bond was related to the stability of the exo versus endo-transition state of the reaction. On the other hands, Mascareñas suggested a stepwise [4+2] mechanism in which intermediate $I$ reacts with the nucleophilic diene affording a new nitrogen stabilized cationic intermediate II. Final intramolecular enamide attack over the less encumbered carbon atom in intermediate II furnishes the final [4+2] cycloadduct after deauration. The control experiments realised performing the reaction between allenamides and dienes in the presence of methanol supported the consistency of the proposed stepwise mechanism. Moreover, the proposed reaction mechanism accounts for the isolation, in low yields, beside the [4+2] products, of the [2+2] cycloadducts arising from intermediate II by intramolecular nucleophilic attack of enamide over the internal carbon atom of the allyl moiety. The amount of [2+2] products strictly depends on the nature of the catalyst used even if the authors did not evaluate the conditions for the exclusive formation of the cyclobutane derivatives. For example, IPrAuCl/AgSbF 6 triggers the reaction toward the formation of [4+2] and [2+2] cycloaddition products in 41 and $16 \%$ yield, respectively.

Starting our studies for the reaction of 2-vinylindoles with allenamides,,$^{[9]}$ scheme 8 , we found that the use of vinylindoles $1 \mathbf{a}$-b bearing methyl or hydrogen at $\mathrm{N} 1$ gave rise to hydroarylation products $\mathbf{1 0}$ in moderate yields when using the cationic gold catalyst $\left[\mathrm{Au}\left(\mathrm{PPh}_{3}\right)\left(\mathrm{NTf}_{2}\right)\right]$.

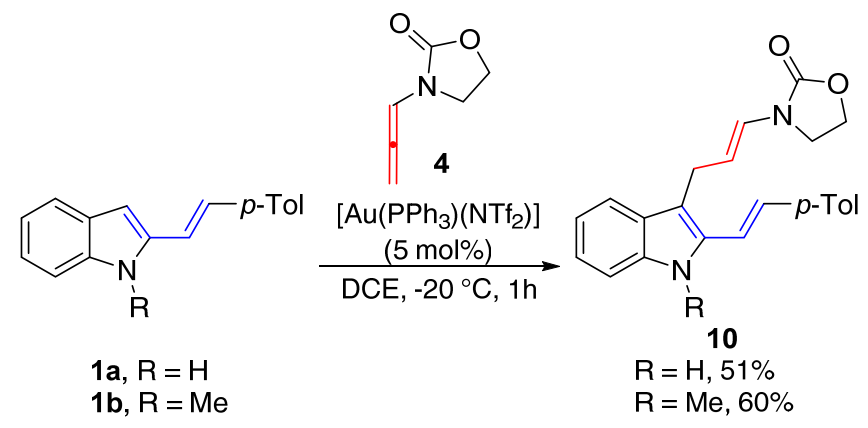

Scheme 8. Gold-catalysed reaction between NH/N-Me 2-vinylindoles 1a-b and allenamide 4.

Indeed, when we employed vinylindole 1c, table 1, bearing a carbamate at nitrogen, under the previous reaction conditions, the 3amidomethyliden-tetrahydrocarbazole 5 arising from a [4+2] cycloaddition/[1,3]hydrogen shift process was isolated along with a nonaromatized carbazole 11 arising from a simple [4+2] cycloaddition process not followed by hydrogen shift and an unexpected tetrahydrocarbazole 12. It is worth to note that all tetrahydrocarbazoles were obtained as single chemo-, regio- and diastereoisomers as demonstrated by single crystal X-ray analysis. Moreover, compound $\mathbf{1 2}$ arises from a three components process involving one molecule of vinylindole and two molecules of the allene, a process that is less common in gold catalysis and not reported before in cycloadditions with allenamides. Thus, a more detailed study was carried out in order to identify the best reaction conditions for the selective synthesis of $\mathbf{5}, 11$ and 12 , table 1 .

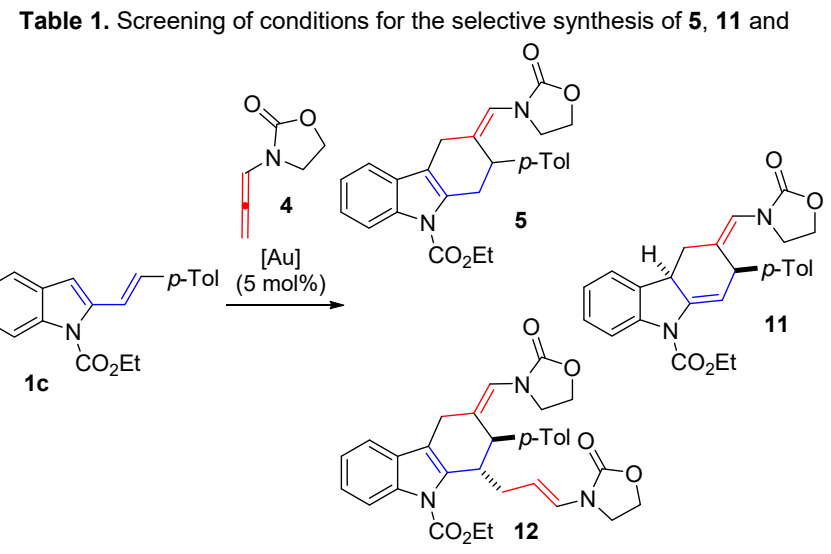

12

\begin{tabular}{ccccccc}
\hline Entry ${ }^{[a]}$ & $\begin{array}{c}\mathbf{4}, \mathrm{n} \\
\text { equiv. }\end{array}$ & {$[\mathrm{Au}](5 \mathrm{~mol} \%)$} & $\begin{array}{c}\text { Solvent } \\
{[\mathrm{M}]}\end{array}$ & $\begin{array}{c}\mathbf{5} \\
(\%)\end{array}$ & $\begin{array}{c}\mathbf{1 1} \\
(\%)\end{array}$ & $\begin{array}{c}\mathbf{1 2} \\
(\%)\end{array}$ \\
\hline 1 & 0.9 & {$\left[\mathrm{Au}(\mathrm{IPr})\left(\mathrm{NTf}_{2}\right)\right]$} & $\begin{array}{c}\mathrm{DCE}, \\
0.1 \mathrm{M}\end{array}$ & 5 & 75 & - \\
\end{tabular}




\begin{tabular}{|c|c|c|c|c|c|}
\hline 2 & 0.9 & {$\left[\mathrm{Au}(\mathrm{JohnPhos})\left(\mathrm{NTf}_{2}\right)\right]$} & $\begin{array}{l}\text { DCE, } \\
0.1 \mathrm{M}\end{array}$ & - & 81 \\
\hline 3 & 0.9 & {$\left[\mathrm{Au}\left(\mathrm{PPh}_{3}\right)\left(\mathrm{NTf}_{2}\right)\right]$} & $\begin{array}{l}\text { DCE, } \\
0.1 \mathrm{M}\end{array}$ & 54 & - \\
\hline 4 & 0.9 & {$\left[\mathrm{Au}\left((\mathrm{ArO})_{3} \mathrm{P}\right)\left(\mathrm{NTf}_{2}\right)\right]$} & $\begin{array}{l}\text { DCE, } \\
0.1 \mathrm{M}\end{array}$ & 65 & 18 \\
\hline 5 & 0.9 & {$\left[\mathrm{Au}(\mathrm{JohnPhos})\left(\mathrm{NTf}_{2}\right)\right]$} & $\begin{array}{c}\mathrm{CH}_{2} \mathrm{Cl}_{2}, \\
0.05 \mathrm{M}\end{array}$ & - & 80 \\
\hline 6 & 2.5 & {$\left[\mathrm{Au}(\mathrm{JohnPhos})\left(\mathrm{NTf}_{2}\right)\right]$} & $\begin{array}{c}\mathrm{CH}_{2} \mathrm{Cl}_{2}, \\
0.05 \mathrm{M}\end{array}$ & - & - \\
\hline $7^{[b]}$ & 0.9 & $\mathrm{AuCl}_{3}$ & $\begin{array}{l}\mathrm{CH}_{2} \mathrm{Cl}_{2}, \\
0.05 \mathrm{M}\end{array}$ & 83 & - \\
\hline
\end{tabular}

[a] Isolated yields. [b] Performed at $-50^{\circ} \mathrm{C}$.

$\mathrm{IPr}=$ Chloro[1,3-bis(2,6-diisopropylphenyl)imidazol-2-ylidene]; JohnPhos = (2-Biphenyl)di-tert-butylphosphine; $\mathrm{Ar}=$ 2,4-di-t-butylphenyl.

We performed a first screening in the presence of 0.9 equivalents of allenamide with various gold catalysts and those giving rise to superior selectivity are listed in table 1 from entry 1 to entry 4 in roughly increasing order of electrophilicity. ${ }^{[16]}$ They are all preformed cationic species with triflimide as counterion and as ligands a heterocyclic carbene, two phosphines (JohnPhos and $\left.\mathrm{PPh}_{3}\right)$ and a more electrophilic triarylphosphite. Next, further experiments were conducted for the synthesis of 11 and in particular, using [Au(JohnPhos)(NTf $)$ ] a dilution of the reaction mixture resulted in the isolation of $\mathbf{1 1}$ in $80 \%$ yield as single reaction product (entry 5 ). The selective synthesis of multicomponent product 12 in $95 \%$ yield was achieved under the same reaction conditions using of an excess of allene (entry 6). Moreover, we found that the use of simple electrophilic $\mathrm{Au}(\mathrm{III})$ chloride favours the aromatization process affording $\mathbf{3}$ as single product in $83 \%$ yield (entry 7 ). Having the optimized reaction conditions for the selective synthesis of $\mathbf{5}$, $\mathbf{1 1}$ and 12, we next evaluated the scope of these cycloadditions. Wide reaction scope was observed and modifications at the vinyl moiety and at the indole core as well as at the allenamide function are well tolerated. For the reactions performed with $\mathrm{N}$-tosylallenamides a loss of stereoselectivity at the exocyclic double bond is somewhat observed. Finally, we found that the reaction works well also with allenamides and 2-vinylbenzofurane or 3-stirylindole as dienophiles. Due to the high polar character of the reacting substrates and intermediates, we assumed that the reaction proceeds via a fast stepwise path, scheme 9 . 


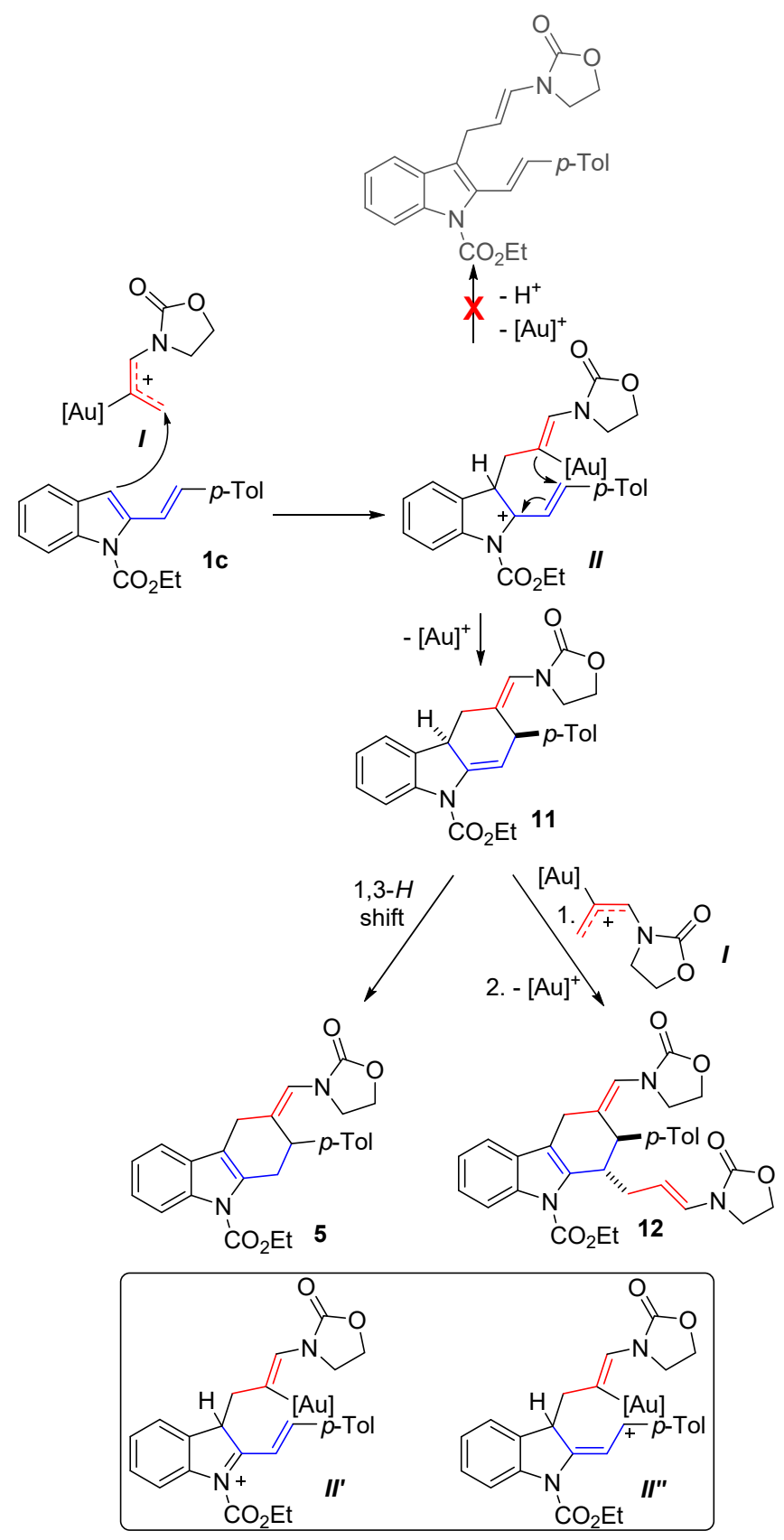

Scheme 9. Proposed mechanism for the reaction between 4 and 1c.

A plausible mechanistic rationale ${ }^{[17]}$ comprises the formation of the gold-allyl cation $\boldsymbol{I}$ followed by the nucleophilic attack of the indole through position C-3 affording intermediate II. Then cyclisation occurs, in a process, which is faster than protodemetallation. This cyclisation leads to carbazole 11, which in turn evolves to the aromatised indole 3 or undergoes a hydroarylation reaction with a second molecule of gold-activated allene $\boldsymbol{I}$ to afford 12 after aromatisation and protodemetallation. The driving force to the exclusive formation of the cycloaddition product over the hydroarylation reaction could be related to the presence of the EWD group at N1 that can lower the nucleophilic character of the indole nitrogen, and thus the relative contribution of cationic species II' and II' with respect to II. The enhanced electrophilic character of the outer carbon atom of the vinyl system favours the cyclisation process.

Apart from allenamides, we were interested in expanding the reaction to other allenes. ${ }^{[18]}$ However, the use of other allenyl derivatives, such as allenyl ethers 8, led to unsatisfactory results in terms of E/Z selectivity and yield, scheme 10. 


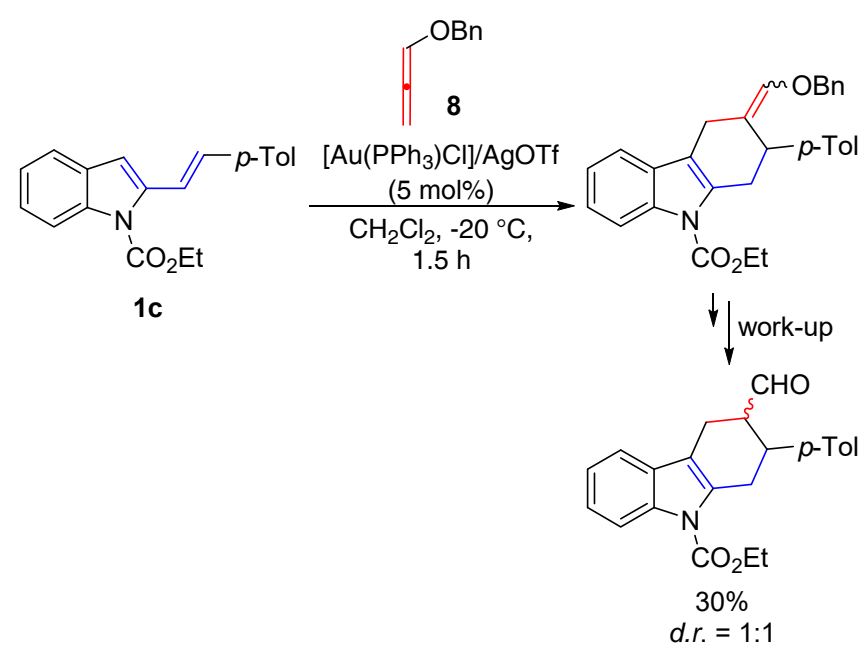

Scheme 10. Gold-catalysed reaction between 1c and allenyl ether 8.

Furthermore, purification of the reaction crude led to isolation of the corresponding aldehydes, arising from hydrolysis of the vinyl ether group, as a 1:1 mixture of diasteroisomers. To address these difficulties, we envisioned the possibility of using allenyl esters as allenyl ether surrogates, scheme 11.

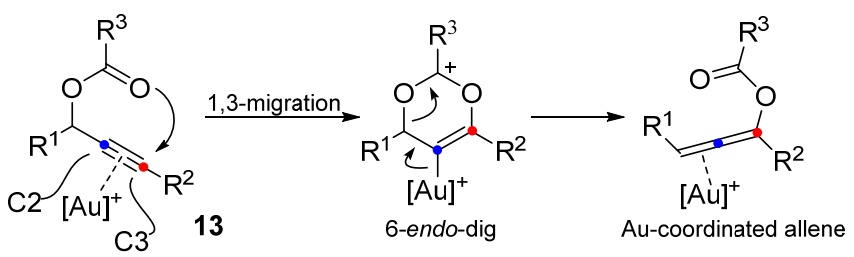

Scheme 11. Generation of allenyl esters by gold-catalysed [3,3]-propargylic rearrangement of propargyl esters 13.

Importantly, allenyl esters can be prepared from propargyl esters 13 via 3,3-rearrangement in the presence of cationic gold(I) catalysts and the use of highly electrophilic cationic gold catalyst enables not only the generation of the allenyl ester but also its subsequent activation for further transformations via cascade reactions. ${ }^{[19]}$ So for our purposes both the [3,3]-propargylic rearrangement of 13 and [4+2] cycloaddition could be catalysed by the same gold species giving access to functionalised products via a cascade reaction. As expected the catalyst of choice was the electrophilic cationic gold(I) tris(2,4-di-tert-butylphenyl)phosphite and optimization of the reaction condition led to the isolation of the desired carbonyloxymethyliden-tetrahydrocarbazole 14 in $75 \%$ yield, scheme 12 . 

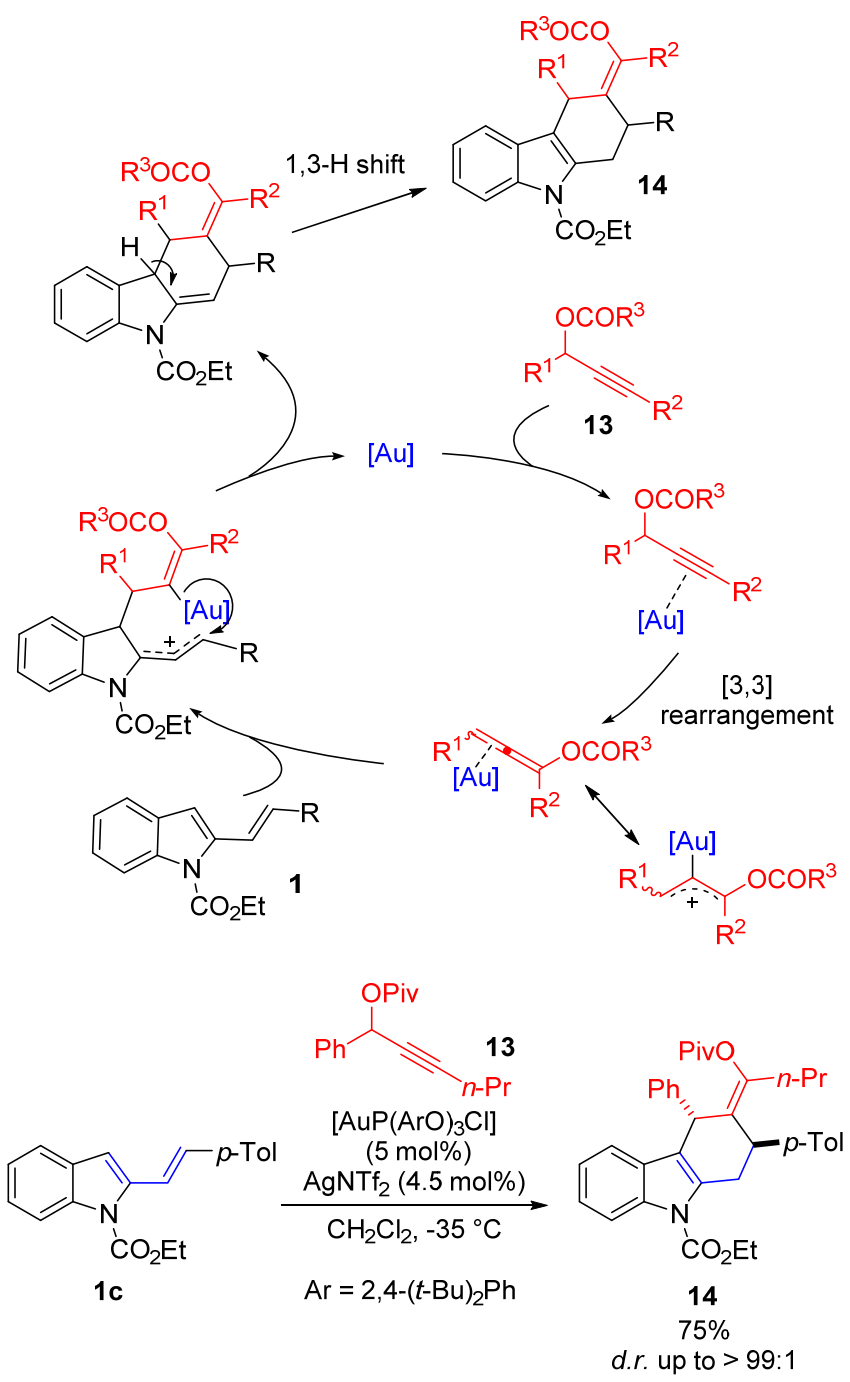

Scheme 12. Gold-catalysed cascade [3,3]-propargylic rearrangement/[4+2]-cycloaddition of 2-vinylindoles 1 and propargyl esters 13 .

According to the screening, we then studied the scope of the present transformation. Modifications at the indole nucleus as well as at the propargyl alcohol are allowed and the corresponding tetrahydrocarbazoles 14 were obtained in good yields. In addition, terminal alkyne could participate in these reactions even if the product was obtained in modest $35 \%$ yield.

Finally, we focused our attention on the enantioselective version of these and related reactions. Achieving enantioselectivity by means of gold catalysis is a challenging goal because both the linear two-coordination mode of gold $(\mathrm{I})$ complexes and the out-sphere $\pi$ activation mode, place chiral ligands far apart from the reacting centre, thus limiting the capacity to transfer the chiral information to the substrates. ${ }^{[20]}$ A number of strategies to overcome this problem have been developed, most of them based on the use of new bulky chiral gold complexes with different steric and electronic properties. In a work which represents the evolution of that shown in scheme 6. Mascareñas and co-workers reported the first example of a highly enantioselective intermolecular [4+2] cycloaddition between allenamides 4 and acyclic dienes 7 catalysed by a chiral cationic gold(I) complex. ${ }^{[21]}$ The work also represents the first asymmetric intermolecular [4+2] cycloaddition promoted by a chiral carbophilic metal complex, scheme 13. 
<smiles>[R]C=C([R])C([R])=C[R]</smiles>

7<smiles>O=C1CCCN1C=CC=[Rh]</smiles>

4

$\mathrm{R}^{4}=\mathrm{H}$, Alk $\mathrm{R}^{5}=\mathrm{H}, \mathrm{Me}$

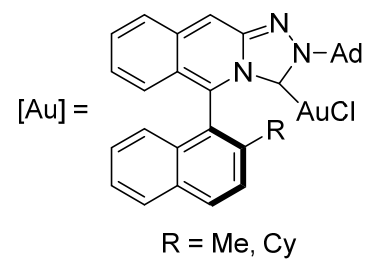

Scheme 13. Enantioselective [4+2]-cycloaddition between 7 and 4

The reaction provided a variety of cyclohexenone derivatives 9 with ee up to $99 \%$ using as ligand for the gold $(\mathrm{I})$ a new chiral carbene featuring a triazole-based NHC fused to a rigid C-2 asymmetric framework. The design of this new catalyst started with the observation that achiral NHC were able to catalyse the reaction and that chiral triazole-based NHCs have been successfully used in asymmetric organocatalysis. ${ }^{[22]}$ The evolution from known ligands to the new chiral ones is reported in figure 1.<smiles>Cc1cc(C)c(N2N=C3COC4Cc5ccccc5C4N3C2[C@H](C)Cl)c(C)c1</smiles>

A

High yield, low e.e.<smiles>[R]CN1C([M])C2=NN(c3ccccc3)C([M])N21</smiles>

B

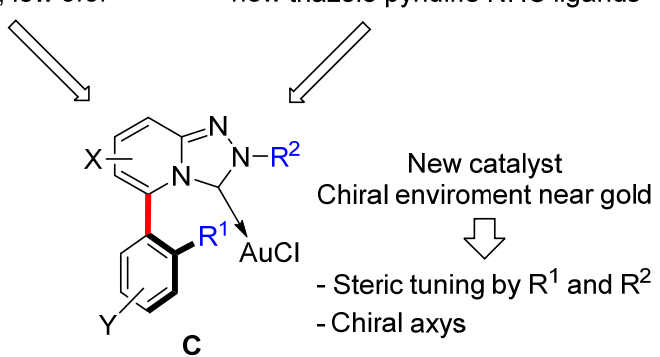

High yield, high e.e.

Figure 1. Design of chiral triazole-based NHCs

Bode's triazolylidene chiral ligand $\mathbf{A}^{[23]}$ promoted the formation of cyclohexenones in $91 \%$ yield and $16 \%$ ee. On the other hand, the research group of Lassaletta synthesised, inter alias, a new class of $[1,2,4]$ triazolo[4,3-a]pyridin-3-ylidene $\mathrm{NHC}$ ligands $\mathbf{B}$. ${ }^{[24]}$ On these basis Mascareñas and co-workers designed and synthesised a new type of gold complexes $\mathbf{C}$. The effectiveness of this catalyst can be related to the proximity of the cyclohexyl substituent $R^{1}$ to the gold center and to the modulatory effect exerted by the bulky adamantly group $\mathrm{R}^{2}$.

Moreover, Bandini developed a dearomative formal [2+2]-cycloaddition reactions involving indoles 15 and allenamides 4 and giving rise to 2,3-cyclobutane-fused indolines 16. DTBM-Segphos, a dinuclear chiral gold catalyst, was used to achieve the desired compounds with ee up to $99 \%$, scheme $14 .{ }^{[25]}$ 


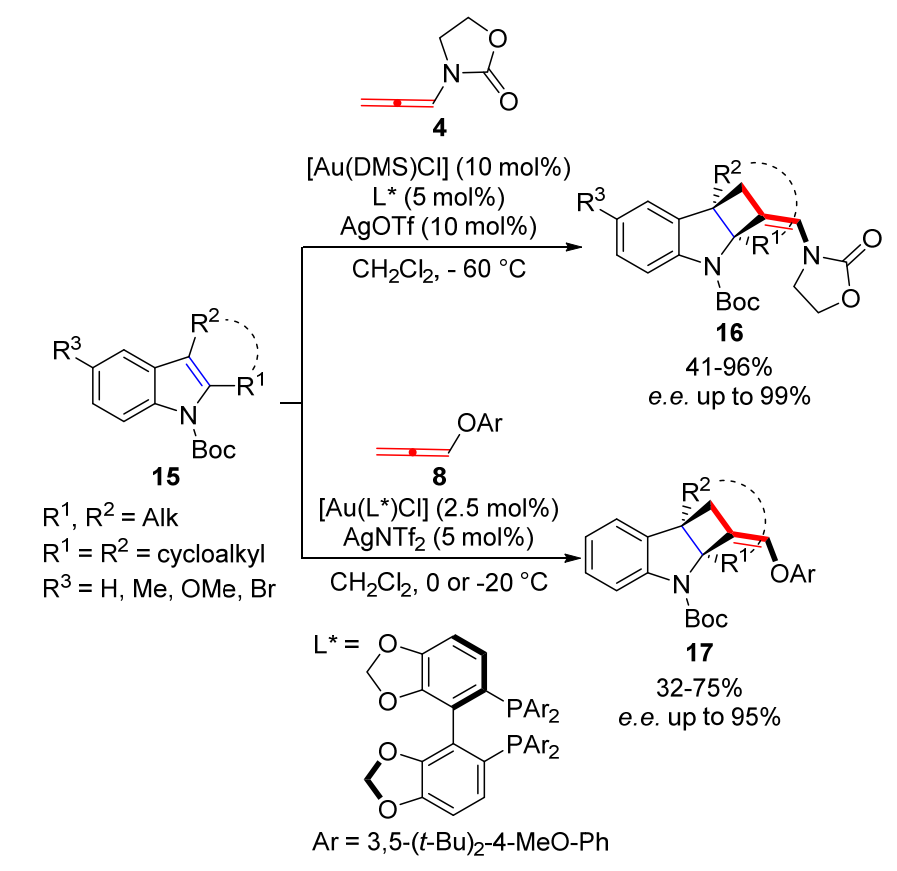

Scheme 14. Dearomative [2+2] cycloadditions of indoles 15 and allenes 4 and 8

The screening for the best chiral ligand was performed using commercially available mono and dinuclear ligands. The gold(I) complex showing the best performances in the primary screening was then used for the fine tuning of the counter ion for the cationic gold $(I)$ complex and of the reaction conditions. Bandini and co-workers expanded the scope of these dearomative [2+2] cycloadditions to aryloxyallenes 8 (scheme 14) for the synthesis of 2,3cyclobutane-fused indolines $\mathbf{1 7}$. Moreover, they combined the experimental work with a computational study demonstrating that the reaction proceeds via a two-step process, scheme 15. ${ }^{[26]}$ 

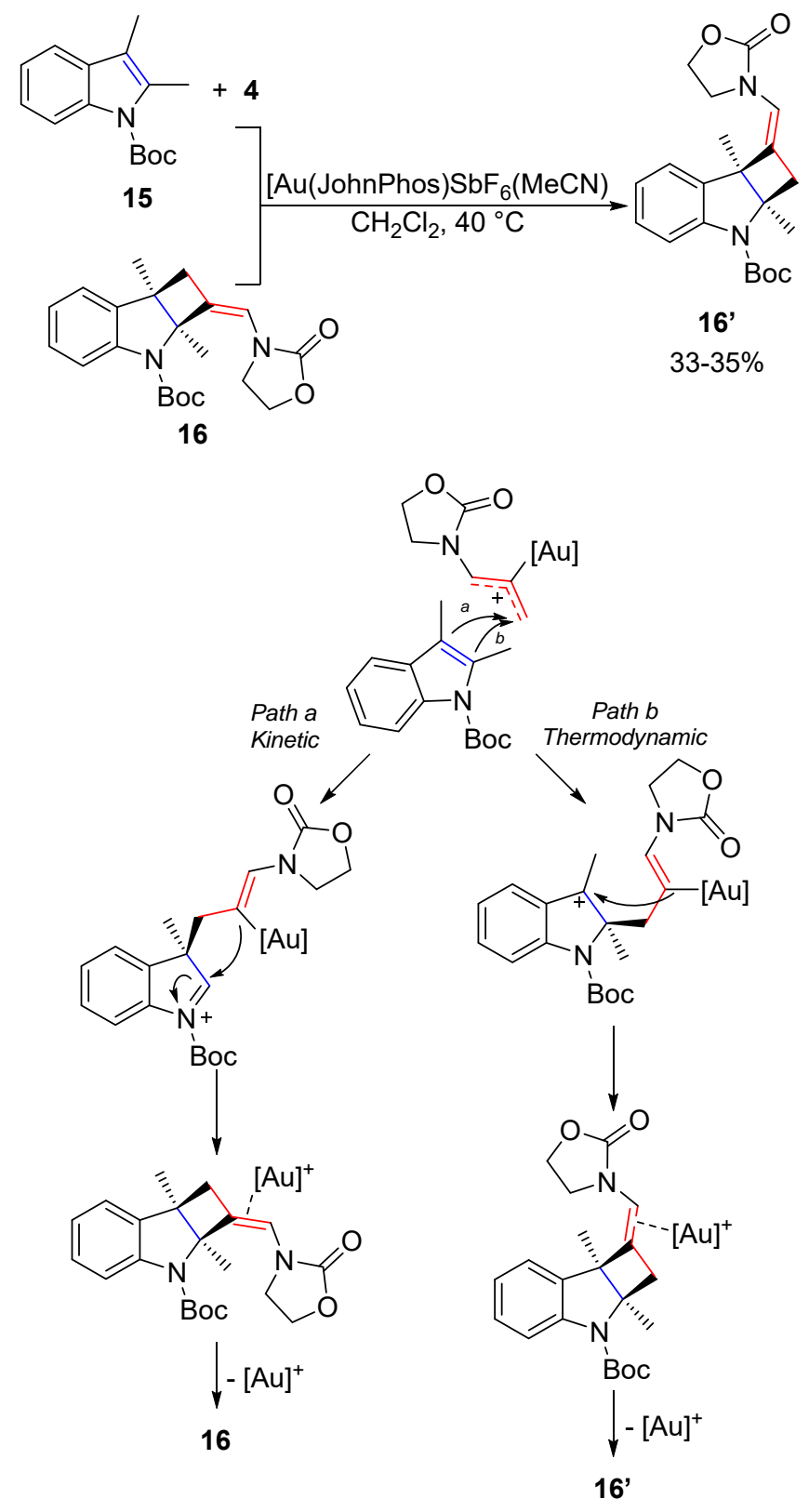

Scheme 15. Formation of regioisomeric 16' and proposed two steps polar non-concerted mechanism.

In particular, they noticed that when the reaction was conducted at $40^{\circ} \mathrm{C}$ regioisomeric [2+2] cycloadducts $16^{\prime}$ ' was the main reaction product. Moreover, 16' was formed also by treating 16 at $40^{\circ} \mathrm{C}$ with the gold $(\mathrm{I})$ complex suggesting the existence of a kinetic (16) and a thermodynamic (16') compound. Thus, a detailed computational study demonstrated the existence of two reaction pathways both involving a two steps polar non-concerted mechanism. Both reaction paths start from a common initial complex in which the indole ring and the metal allyl cation planes face each other. Then two separate reaction paths provide the two regioisomers detected experimentally. Regioisomer $\mathbf{1 6}$ obtained under kinetic control and 16' under thermodynamic conditions. It is worth to note that the second step in both reactions involves the formation of the cyclobutene ring through the heterolytic rupture of the sigma [Au]-C bond and not the electrons of the exocyclic double bond. This observation accounts for the retention of the $\mathrm{Z}$ stereochemistry for the $\mathrm{C}=\mathrm{C}$ double bond.

In this context, we studied the enantioselective version of our cascade reactions between 2-vinylindoles 1 and propargyl esters ${ }^{[11]} \mathbf{1 3}$ and between a new class of 2-vinylindoles 17 , bearing a methyl group at C-3 position, with allenamides $4^{[27]}$ for the synthesis of enantioenriched tetrahydrocarbazoles 14 and dearomatized indole derivatives 18, scheme 16. 


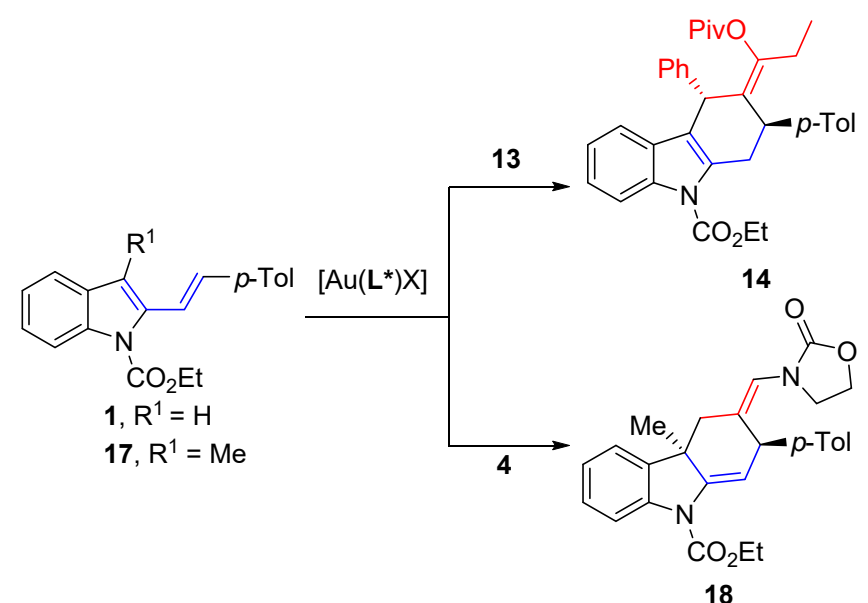

Scheme 16. Gold-catalyzed enantioselective synthesis of 14 and 18.

In the first screening, table 2, we tested several chiral electronrich phosphoramidites ligands pertaining to the class of BINOL and spirobiindane derivatives $\left(L_{1}-L_{4}\right)$ and a chiral phosphite ligand $\left(L_{5}\right)$. All these ligands deliver high electrophilic cationic gold $(I)$ complexes that would be able to trigger both the $[3,3]$ rearrangement of the propargyl alcohol to allenyl ester and the formation of the corresponding gold-activated species.

Table 2. Optimization of conditions for the synthesis of 14

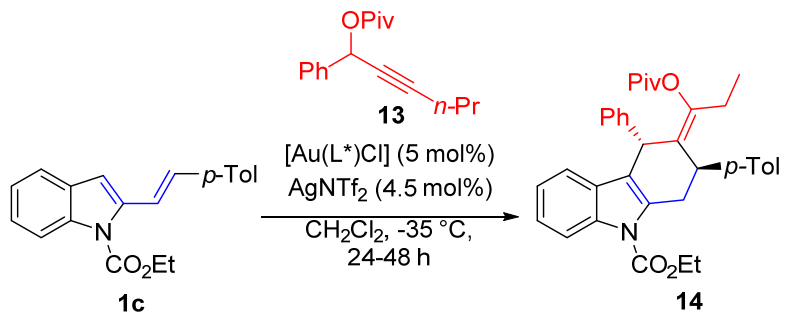

\begin{tabular}{llllll}
\hline Entry & $\mathrm{L}^{*}$ & Additive & Time, h & Yield $(\%)^{[\mathrm{a}]}$ & ee \\
\hline 1 & $\mathrm{~L}_{1}$ & - & 24 & 90 & 20 \\
2 & $\mathrm{~L}_{2}$ & - & 24 & 43 & 60 \\
3 & $\mathrm{~L}_{3}$ & - & 48 & 47 & 62 \\
4 & $\mathrm{~L}_{4}$ & - & 48 & 42 & 68 \\
5 & $\mathrm{~L}_{4}$ & $4 \AA \mathrm{MS}$ & 48 & 62 & 70 \\
6 & $\mathrm{~L}_{5}$ & - & 24 & 33 & 14 \\
\hline
\end{tabular}

[a] Isolated yields.<smiles></smiles>

$L_{1}: R=H$

$L_{2}: R=$ naphty

$L_{3}: R=$ pyreny<smiles>CC(c1ccccc1)N(CP(Oc1cccc2c1CCC2)c1ccccc1)c1ccccc1</smiles>

$\mathrm{L}_{4}$<smiles>CC(=O)Oc1ccc2ccccc2c1-c1c(OC(F)(F)F)ccc2ccccc12</smiles>

$L_{5}$

In general, what we observed with all the ligands screened was a general and consistent decrease of the reaction rate, which determines also a degradation of the starting allene during the reaction with a consequent decrement in the final yields. Spirobiindane ligand $\mathbf{L}_{4}$ 
gave the best results in terms of yield and enantioselection when the reaction was performed in the presence of $4 \AA$ molecular sieves (entry 5). Under these conditions, tetrahydrocarbazole 14 was obtained in $62 \%$ yield in moderate $70 \%$ ee. The moderate ee's obtained and the lack of chiral ligands with different architectures and low electrondonor abilities prompted us to stop our investigation at the screening level without investigating the scope of the transformation.

With C3 alkyl substituted 2-vinylindoles 17 we decided to come back to allenamides 4 as dienophiles and tested their reaction under chiral gold(I) catalysis, scheme 17.<smiles>CCOC(=O)/C=C/c1c(C)c2ccccc2n1CCO</smiles>

17<smiles>C=CCN1CC(C)CO1</smiles>

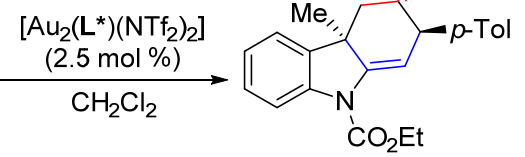

18

$\mathrm{L}_{1}:-40^{\circ} \mathrm{C}, 85 \%, 92 \%$ e.e.

$\mathrm{L}_{2}:-20^{\circ} \mathrm{C}, 54 \%, 50 \%$ e.e.

$\mathrm{L}_{3}:-20^{\circ} \mathrm{C}, 52 \%, 26 \%$ e.e.

$\mathrm{L}_{4}:-20^{\circ} \mathrm{C}, 75 \%, 60 \%$ e.e.

$L_{5}:-20^{\circ} \mathrm{C}, 48 \%, 76 \%$ e.e.

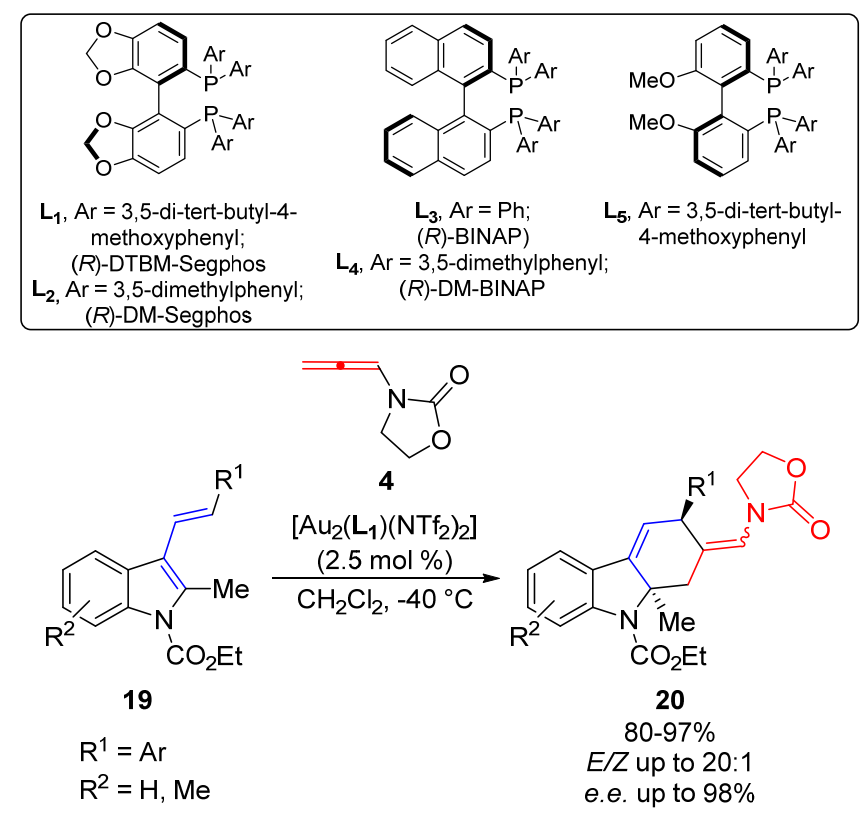

Scheme 17. Gold-catalysed enantioselective synthesis of carbazoles 18 and 20.

This reaction would lead to interesting dearomatised tetrahydrocarbazoles 18 bearing a quaternary stereocenter. However, we needed to consider the reduction of nucleophilicity of a C-3 alkyl substituted indole and in general of its reactivity due to steric effects. In this case, we based the catalysts screening for the dearomative reaction on the use of diphosphine ligands. In particular, using DTBM Segphos $\left(L_{1}\right)$, under optimized reaction conditions, we obtained the dearomatized carbazole in $85 \%$ yield and in $92 \%$ ee. As reported in scheme 17 other chiral dinuclear gold catalysts gave worst results. Having the optimised conditions, we tested various 3-substituted 2 -vinylindoles and the corresponding products were isolated with high yields and generally high enantioselectivities. Switching from allenamides to $\mathrm{N}$-tosylallenamides loss of enantioselectivity was observed. Besides 2-vinylindoles, we briefly expanded the scope of our reaction to 2-methyl-3-vinylindoles 19. In this case, the reaction afforded the corresponding dearomatised indoles 20 as E/Z isomers on exocyclic double bond, although in overall excellent yields. After an easy separation on column chromatography, chiral HPLC revealed that both isomers were formed with excellent ee.

In 2015, the research group of prof. Zhang reported a comprehensive study on the behaviour of 3-vinylindoles in the chiral gold(I) catalysed reactions with $N$-tosyl allenamides $21^{[28]}$ As reported by us, they observed that the protecting group at the indole nitrogen exerts a deep influence on the reaction outcome. In particular, they found that $\mathrm{N}$-alkyl substituted indoles give [2+2] cycloadducts 22 whereas $\mathrm{N}$-carbamate protected vinylindoles, [4+2] cycloadducts 23. Both transformations were realised in their enantioselective versions, scheme 18. 


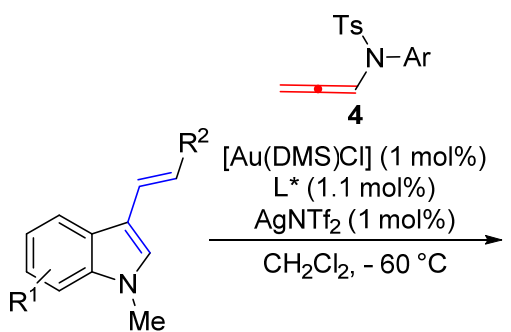

21

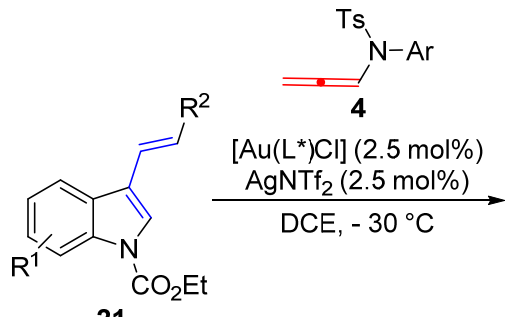

21

$\mathrm{R}^{1}=\mathrm{H}, \mathrm{Br}, \mathrm{MeO}$

$\mathrm{R}^{2}=\mathrm{Ar}, n-\mathrm{Pr}$

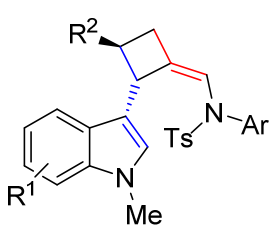

22

$58-99 \%$

e.e. up to $96 \%$

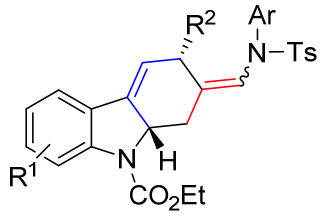

23

88-99\%

Z/E up to $14: 1$ e.e. up to $97 \%$

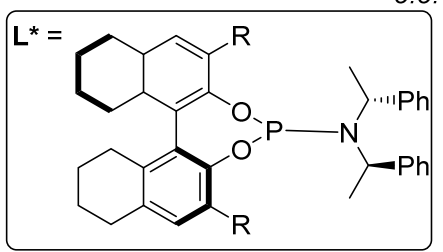

Scheme 18. Gold-catalysed enantioselective [2+2] and [4+2] cycloadditions with 3-vinylindoles 21 and allenamides 4.

At the beginning, they searched for the best reaction conditions to obtain stereoselectively [2+2] cycloadducts and using a phosphoroamidite ligand bearing a saturated cyclohexyl moiety the desired compounds were obtained with ee up to $96 \%$. Then, [4+2] cycloadditions were realised with the same catalytic system with $\mathrm{N}$-carbamate protected 3-vinylindoles 21 and $\mathrm{N}$-tosyl allenamides $\mathbf{4}$. Both $Z$ and $E$ isomers of the corresponding tetrahydrocarbazole $\mathbf{2 3}$ were isolated in high overall yields and with with ee up to $97 \%$ for the $\mathrm{Z}$ isomer and up to $92 \%$ for the $\mathrm{E}$ isomer. The author then realised a detailed computational study to understand the origin of the substituent impact on the cycloaddition mode, figure 2.<smiles>C=Cc1cn(C)c2ccccc12</smiles><smiles></smiles>

Figure 2. Impact of $\mathrm{N}$-substituent on the reactivity of 3-vinylindoles.

The obtained results are in agreement with theoretical calculation shoving that the most reactive positions towards the addition to electrophilic gold-activated allenamides are those indicated by the arrows in the picture. The exocyclic double bond for [2+2] cycloadditions and the $\mathrm{C} 2$ of the indole core for [4+2] cycloadditions. More recently, the same authors extended the [2+2] cycloadditions of 3-vinylindoles 21 to allenamides, scheme 19. ${ }^{[29]}$ 


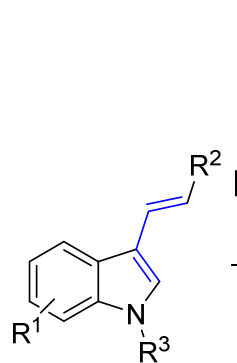

21

$\mathrm{R}^{1}=\mathrm{H}, \mathrm{Br}, \mathrm{Me}$

$\mathrm{R}^{2}=\mathrm{Ar}, \mathrm{Me}$

$\mathrm{R}^{3}=\mathrm{Me}, \mathrm{Bn}$, allyl

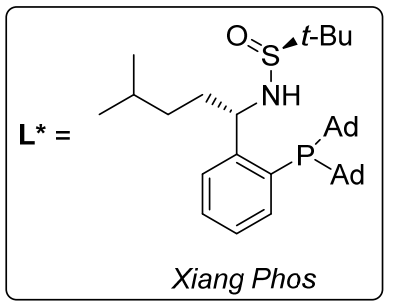

Scheme 19. Extension of [2+2] cycloaddition of $\mathbf{2 1}$ to allenamides.

[2+2] Cycloaddition adducts 22 were obtained in excellent yields and enantioselectivities up to $95 \%$ in the presence of a new XiangPhos chiral ligand pertaining to the class of N,P ligands.

Finally, it is worth to underline the behaviour of 2-vinylindoles and 3-vinylindoles with allenamides or $\mathrm{N}$-tosylallenamides in [4+2] cycloadditions for the synthesis of the corresponding tetrahydrocarbazoles. Both diastereo and enantioselective reactions performed with allenamides result in the synthesis of the corresponding tetrahydrocarbazoles with excellent $Z$ selectivity at the exocyclic double bond. On the contrary, a loss of stereoselectivity was observed when $\mathrm{N}$-tosylallenamides are involved in the [4+2] cycloadditions. As observed by Professor Zhang, steric factors as well as the nature of substrates, catalysts and reaction conditions could influence the reaction outcome.

\section{Reactivity of $4 H$-furo[3,2-b]indoles with gold-activated allenes and gold carbenes}

Recently, we started exploring the synthesis and the behaviour of $4 \mathrm{H}$-furo[3,2-b]indoles with electrophilic gold-activated $\pi$-systems. $4 H$-furo[3,2-b]indoles has been seldom reported in the literature for their promising anticancer and anti-inflammatory/analgesic properties. ${ }^{[30]}$ However, the synthesis of $4 \mathrm{H}$-furo[3,2-b]indoles has been studied essentially in product oriented protocols and their reactivity studied only with regard to simple $\mathrm{N}$ - or $\mathrm{C} 2$ functionalisation reactions. ${ }^{[31]}$ Thus, we synthesised a library of $4 \mathrm{H}$-furo[3,2b]indoles 24 adapting, whenever possible, reported methodologies, ${ }^{[31 d]}$ scheme 20. 


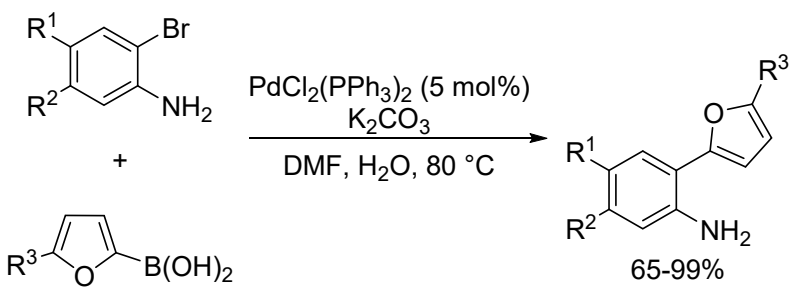

for 24a-g

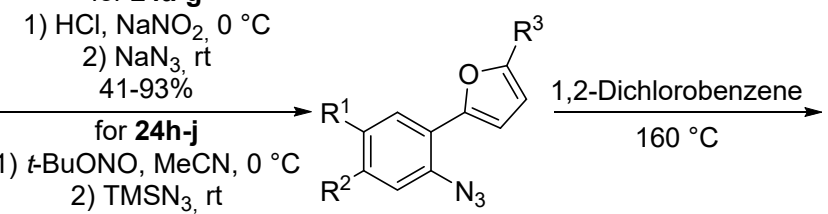<smiles></smiles>

$38-95 \%$<smiles>[R]c1cc2c(o1)c1cc([R])c([R])cc1n2OCC</smiles>

24a-j
24a: $R^{1}=R^{2}=R^{3}=H$
24f: $R^{1}=M e ; R^{2}=H ; R^{3}=H$
24b: $R^{1}=H ; R^{2}=H ; R^{3}=M e$
24g: $R^{1}=F ; R^{2}=H ; R^{3}=H$
24c: $R^{1}=M e ; R^{2}=H, R^{3}=M e$
24h: $R^{1}=H ; R^{2}=F ; R^{3}=M e$
24d: $R^{1}=F ; R^{2}=H ; R^{3}=M e$
24i: $R^{1}=H ; R^{2}=O M e ; R^{3}=M e$
24e: $R^{1}=$ OMe; $R^{2}=H ; R^{3}=M e$
24j: $R^{1}=H ; R^{2}=C F_{3} ; R^{3}=M e$<smiles>CCOC(=O)n1c2ccccc2c2occc21</smiles>

24a

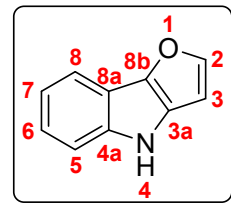<smiles>CCOCn1c2ccccc2c2oc(Br)cc21</smiles>

$79 \%$

$\mathrm{PhB}(\mathrm{OH})_{2}$

$\mathrm{PdCl}_{2}\left(\mathrm{PPh}_{3}\right)_{2}(5 \mathrm{~mol} \%)$

$\mathrm{K}_{2} \mathrm{CO}_{3}$

DMF, $\mathrm{H}_{2} \mathrm{O}, 80^{\circ} \mathrm{C}$<smiles>CCOC(=O)n1c2ccccc2c2oc(-c3ccccc3)cc21</smiles>

24k

$76 \%$

Scheme 20. Synthesis of $4 H$-furo[3,2-b]indoles 24a-k.

Compounds 24a-j, substituted at C2 with a hydrogen or a methyl group, were synthesised in a four-step procedure and protected at $\mathrm{N} 4$ as carbamate to prevent its functionalization in the presence of electrophilic partners. Compound 24k bearing a phenyl substituent at $\mathrm{C} 2$ was prepared via bromination, followed by Suzuki-Miyaura coupling with phenyl boronic acid.

The $4 H$-furo[3,2-b]indole skeleton contains a $4 \pi$-system embedded in the rigid framework of a furan ring. Thus, in principle $4 H$-furo[3,2$b$ ]indoles could take part as dienes or dienophiles in cycloaddition reactions or participate as electronrich heterocycles in reactions with electrophiles, figure 3. 


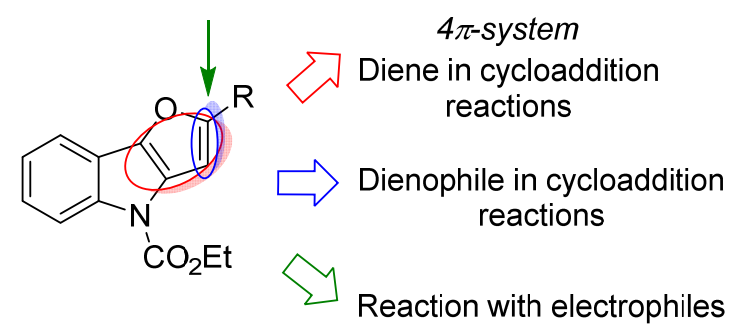

Figure 3. Reactivity of $4 H$-furo[3,2-b]indoles.

At the beginning of our investigation, by analogy, we checked out the existing literature on the reactivity of the furan ring in these and related reactions, schemes $21-24$.

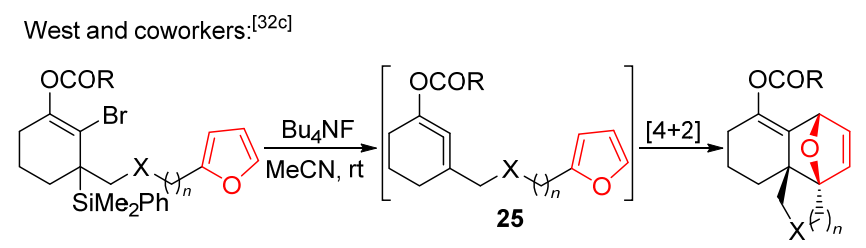

Welch, Harmata and coworkers: ${ }^{[33]]}$

26, $21-79 \%$

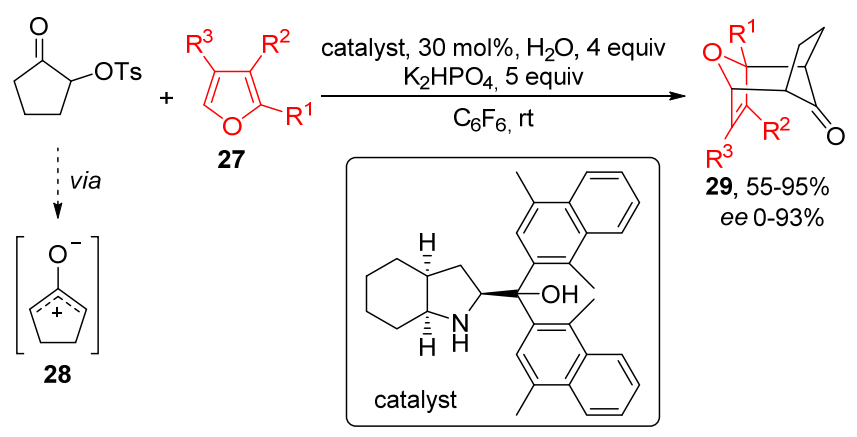

Scheme 21. Furans as dienes in [4+2] and [4+3] cycloaddition reactions.

Thus, furans act as dienes in $[4+2]^{[32]}$ and $[4+3]^{[33]}$ cycloaddition reactions, scheme 21 . Among the most recent examples, in 2019, West and co-workers ${ }^{[32 c]}$ reported on the intramolecular [4+2] cycloaddition between in situ generated cyclic allenes 25 with a tethered furan for the synthesis of tetracyclic compounds 26. Moreover, in 2017, Welch, Harmata and co-workers ${ }^{[33]}$ realised the intermolecular [4+3] cycloaddition between substituted furans and in situ generated allyl cations $\mathbf{2 8}$. The reaction, performed in the presence of a chiral amino alcohol as catalyst enabled the enantioselective synthesis of tricyclic compounds 29 . In these reactions, the furan ring acts as pure diene. However, there are examples in which the furan ring participate in $[4+2]^{[34]}$ and $[5+2]^{[35]}$ formal annulation reactions as dienophile through $\mathrm{C} 2-\mathrm{C} 3$ double bond. The primary adducts in turn can undergo furan ring-opening reactions, scheme 22. 


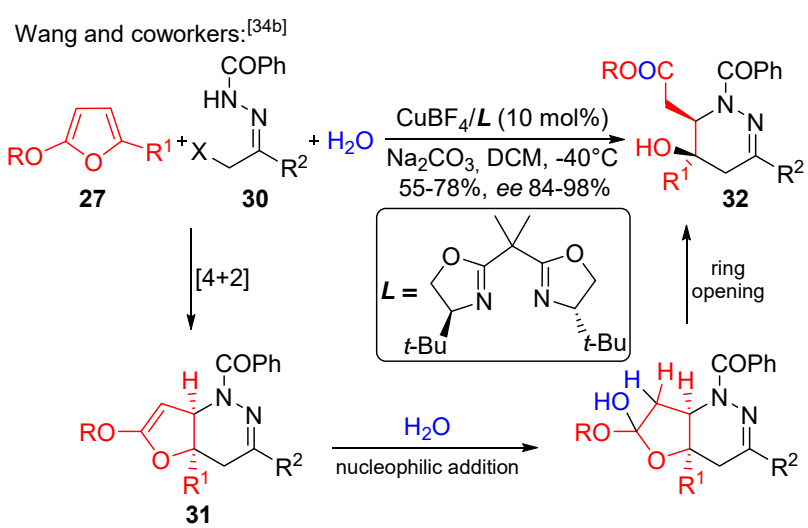

Liu and coworkers: ${ }^{[35]}$<smiles>[R]C#C[C@H](O)[C@H]1CCCC[C@H]1C#C</smiles>

33<smiles>[R]c1ccco1</smiles>

27 catalyst $\stackrel{\text { Condition A or B }}{\longrightarrow}$ 48-73\%<smiles>[R]c1ccc2c(C)cc3c(c2c1C([R])O)CCCC3</smiles>

34

Conditions $A$

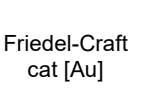

1) $\mathrm{AuCl}_{3}, 5 \mathrm{~mol} \%, \mathrm{rt}, 1.0-2.5 \mathrm{~h}$

2) $\mathrm{AgSbF}_{6}, 15 \mathrm{~mol} \%, 80^{\circ} \mathrm{C}, 1-4 \mathrm{~h}$

Conditions $B$

$\left[\mathrm{Au}\left(\mathrm{PPh}_{3}\right) \mathrm{NTf}_{2}\right], 5 \mathrm{~mol} \%, 80^{\circ} \mathrm{C}, 1-4 \mathrm{~h}$<smiles>[R]C#CC1CCCCC1C(C#C[R])c1ccc([R])o1</smiles>

Scheme 22. Furans in formal C2-C3 double bond annulation/ring-opening reactions.

For example, in 2016, Wang and co-workers reported on the hetero-Diels-Alder reactions of furans 27 in a multicomponent process with azoalkenes 30 and water. ${ }^{[34 b]}$. The reactions performed in the presence of chiral $\mathrm{CuBF}_{4} / \mathrm{t}-\mathrm{Bu}$-Box complex, afforded the corresponding bicyclic compounds $\mathbf{3 1}$ as primary adducts. These latter in the presence of water rearranged by furan ring opening yielding the corresponding tetrahydropyridazines 32 in excellent enantiomeric excesses. A furan ring opening occurs also in the goldcatalysed cascade reaction between 1,6-diynes $\mathbf{3 3}$ and C2 substituted furans $\mathbf{2 7}$ for the synthesis of phenanthrene derivatives $\mathbf{3 4}$. $^{[35]}$ The cascade reaction, reported by Liu and co-workers in 2011, involves inter alias a [5+2] furan-yne cyclisation followed by furan ring rearrangement and hetero enyne metathesis. Finally, the reactivity of furans with electrophilic partners has been investigated in deep and mostly involves addition to $\mathrm{C} 2$ carbon atom, even when this position is already substituted, followed by a ring opening event. ${ }^{[36]}$ These reactions allow for the installation of $\alpha, \beta$-unsaturated carbonyl moieties in a simple and selective manner. In particular, in the field of transition metal catalysis, in 2011. El Kaïm, Grimaud and Wagschal reported a ring opening reaction of furans 35 mediated by a palladium catalyst for the synthesis of $\alpha, \beta$-unsaturated aldehydes and ketones tethered to indole moieties 36 , scheme 23 . ${ }^{[37]}$ 

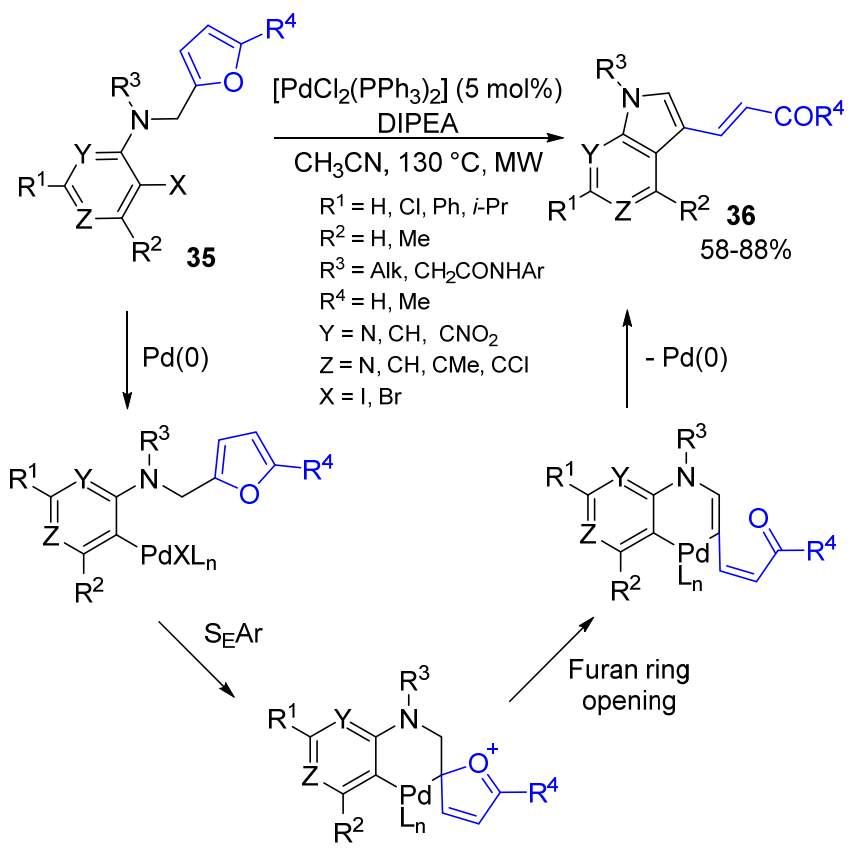

Scheme 23. Furans in reactions with electrophilic partners, Palladium-catalysed electrophilic aromatic substitution/furan ring opening sequence to give 36.

Moreover, in the field of gold catalysis, Echavarren and co-workers described the reactivity of furans 27 with gold(I)-carbenes $\mathbf{3 7}$ generated in situ from propargyl esters 13, 1,6-enynes 38 and 7-substituted-1,3,5-heptatrienes 39, scheme 24. ${ }^{[38]}$
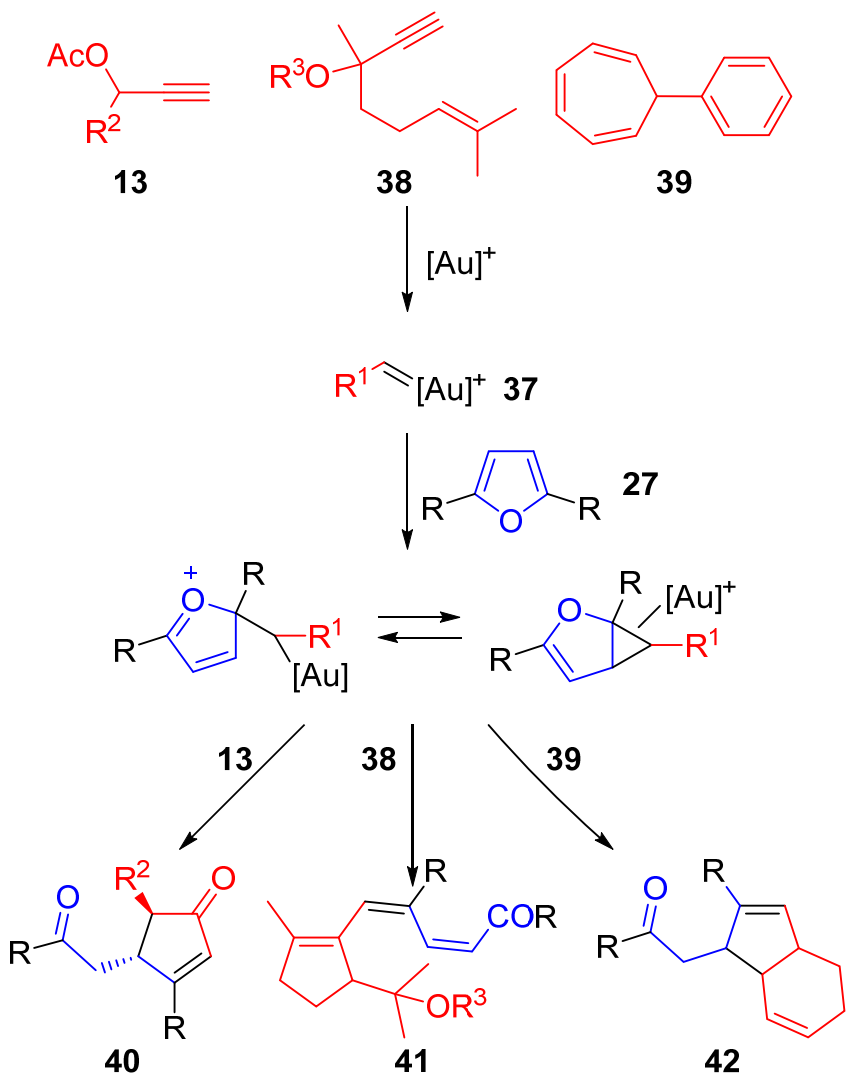

Scheme 24. Furans in reactions with electrophilic partners, reactions between gold(I) carbenes 37 and furans 27.

All these reactions involve the electrophilic addition of gold(I)-carbenes to furans followed by furan ring opening and give rise, respectively, to cyclopentenones $\mathbf{4 0}$, trienyl-carbonyl derivatives $\mathbf{4 1}$ or polycyclic compounds $\mathbf{4 2}$.

Taking into account these premises, we decided to investigate the reactivity of our newly synthesised $4 H$-furo[3,2-b]indoles 24 with two electrophilic partners both generated in the presence of suitable gold catalysts, namely gold-activated allenamides and gold carbenes. 
In particular, we realised a new synthesis of 2-spiroindolin-3-ones $\mathbf{4 3}$ from 2-methyl-4H-furo[3,2-b]-indoles $\mathbf{2 4 b}$-e, $\mathbf{h}$-j and allenamides or $\mathrm{N}$-tosylallenamides 4 in the presence of a preformed cationic gold(I) complex containing a NHC ligand, scheme 25 . ${ }^{[39]}$

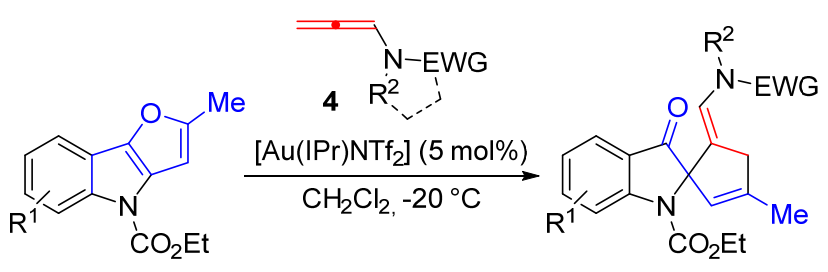

24b-e, h-j

$\mathrm{R}^{1}=\mathrm{H}, \mathrm{Me}, \mathrm{F}, \mathrm{MeO}$

$\mathrm{R}^{2}=\mathrm{Me}, \mathrm{Ph}, \mathrm{Bn},\left(\mathrm{CH}_{2}\right)_{2}$

$\mathrm{EWG}=\mathrm{CO}, \mathrm{Ts}, \mathrm{Boc}$
43

$45-77 \%$

Scheme 25. Gold-catalysed synthesis of spiroindolin-3-ones 43 from 24

The spiroindolin-3-ones $\mathbf{4 3}$ were obtained in good yields with complete stereocontrol at the exocyclic double bond. The choice of the ligand for the gold $(I)$ salt arises from a reaction screening demonstrating that phosphine and phosphite ligands with poorer electrondonor properties than the NHC ligand give rise to the desired compound in lower yields. The reported transformation embodies a new cationic gold $(\mathrm{I})$ catalysed cascade sequence. Thus, the most plausible reaction mechanism involves addition of a gold-activated allene to the furan moiety of the starting furoindole $\mathbf{2 4}$, affording intermediate $\boldsymbol{I}$, followed by a ring-opening/ring-closing event, scheme 26.

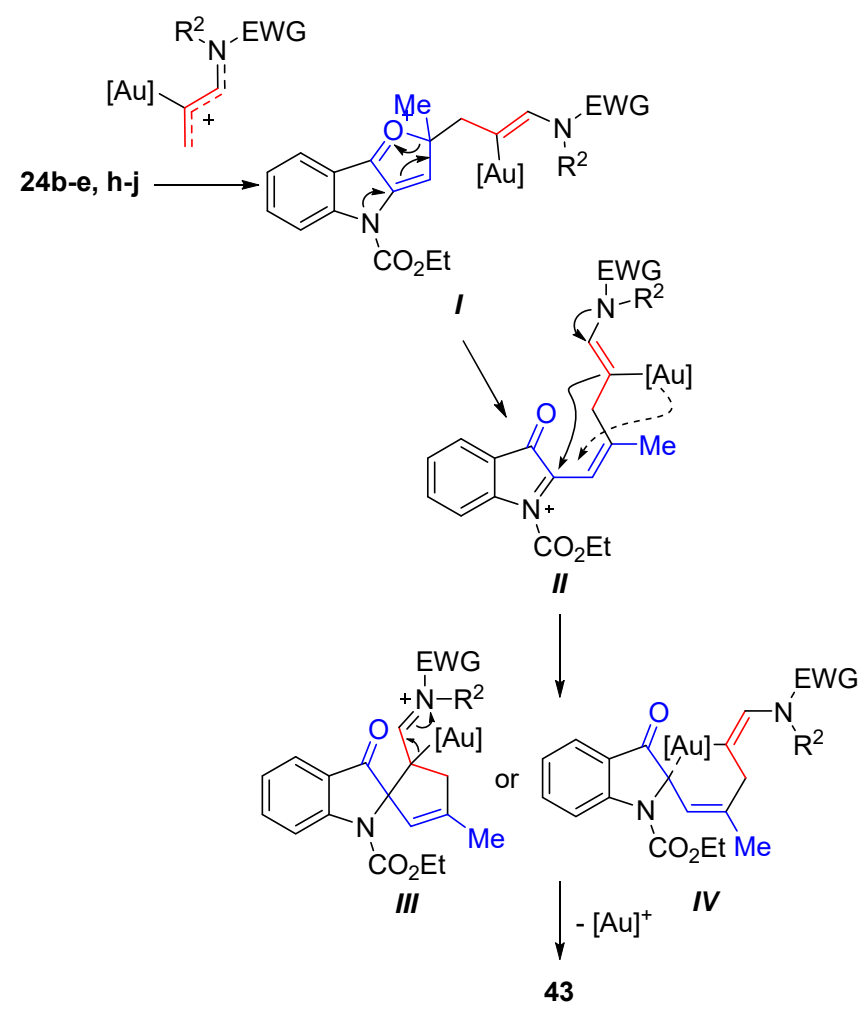

Scheme 26. Proposed mechanism for the synthesis of 43 .

In particular, from intermediate $\boldsymbol{I}$ a rearrangement of the furan ring allows for the formation of iminium indole derivative II. The consequential cyclization of $\boldsymbol{I I}$ followed by elimination of gold(I) provides the final product. The spirocyclisation step may be driven from the enaminone system giving rise to intermediate III or prompted by the formation of the pseudometallacyclic intermediate $I \boldsymbol{V}$ via electrostatic interaction of gold with indole $\mathrm{C} 2$. In accordance with several authors we believe that intermediate IV better explains the stereochemistry at the exocyclic double bond observed in the final products $43 .{ }^{40]}$

From this perspective, in this transformation, the gold catalyst is responsible for both the activation of the allenamide and probably also for the stereocontrol in the spirocyclisation event. The limit of this approach resides in the need to operate with C2-substituted furoindoles to avoid the competitive hydroarylation and rearomatisation sequence observed when C2-unsubstituted furoindoles were employed as substrates. ${ }^{[39]}$ 
Then, we explored the reactivity of our furoindoles 24 with gold(I)-carbene complexes ${ }^{[41]}$ generated in situ from suitable propargyl esters 13 via gold-catalysed 1,2-acyloxy migration ${ }^{[19]}$ As previously mentioned, propargyl esters are useful substrates for cascade reactions. In particular, they are able to generate, via gold-catalysed 1,3- or 1,2-acyloxy migration, gold-coordinated allenes, scheme 11, or goldcarbenes 37 , scheme 27 , depending on the substitution pattern.

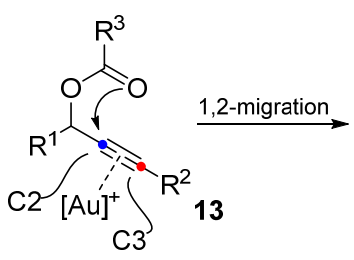

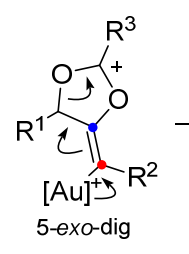<smiles></smiles>

Scheme 27. Propargyl esters, 1,2-acyloxy migration.

As reported in scheme 28, a model reaction between furoindole 24a and propargyl ester 13, performed in toluene and in the presence of preformed cationic $\left[\mathrm{Au}(\mathrm{JohnPhos})\left(\mathrm{SbF}_{6}\right)\right]$ catalyst, afforded a separable 1:1 mixture of Z/E 2-(hepta-2,4,6-trien-1-ylidene)-3oxoindolines 44 and 44 ' in overall $92 \%$ yield, besides a $6 \%$ amount of tetracyclic compounds 45 .

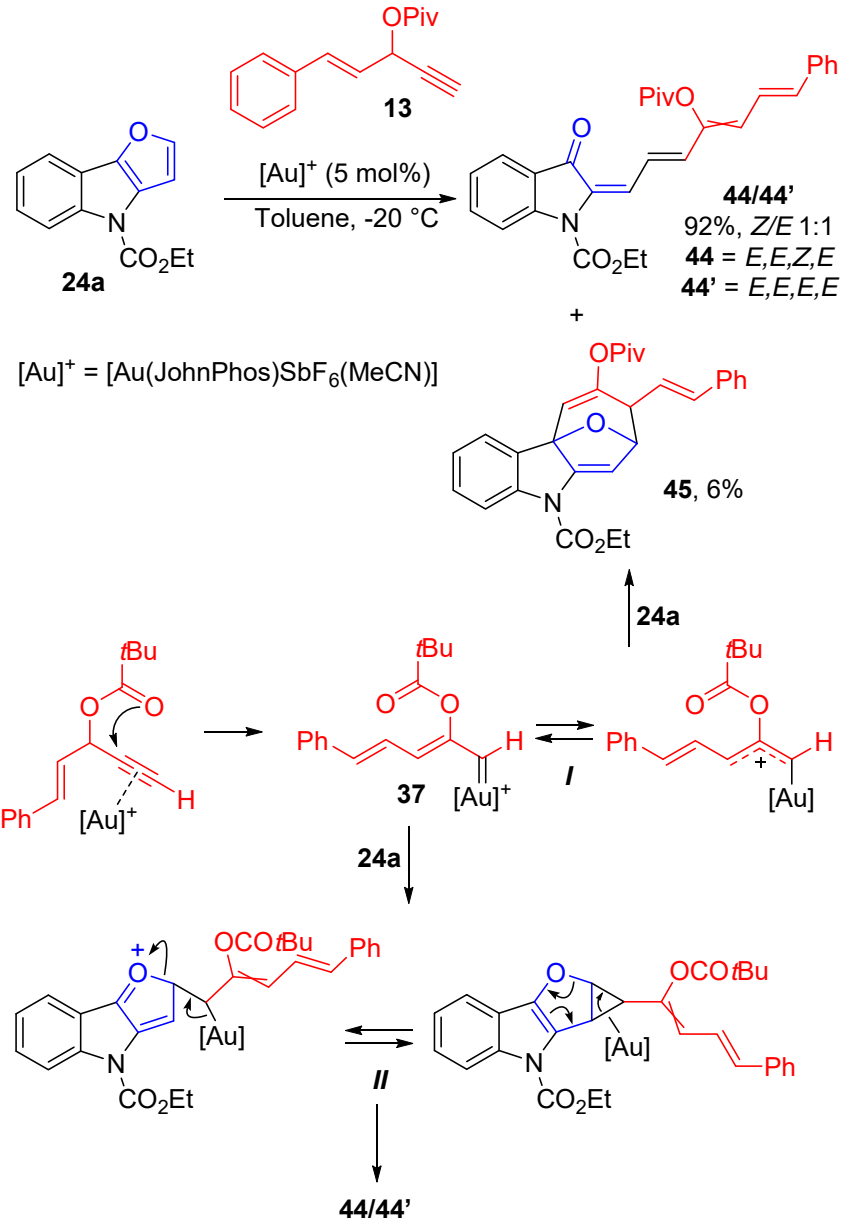

Scheme 28. Reactivity of furoindoles $\mathbf{2 4}$ with gold(I)-carbenes $\mathbf{3 7}$ generated from proparylic ester 13.

The use of catalysts with different electronic properties resulted in poor yields when a less electrophilic catalyst, [Au(IPr)(NTf $)$ ], was employed or in loss of selectivity toward the formation of the 3-oxoindolines 44/44' with respect to tetracyclic compound $\mathbf{4 5}$ when more electrophilic complexes were employed, $\left[(\mathrm{ArO})_{3} \mathrm{PAu}\left(\mathrm{SbF}_{6}\right)\right]$. The proposed mechanism accounts for the stereochemical outcome of the reaction. Thus, the $E / Z$ geometry at the exocyclic trienylidene moiety of 3-oxoindolone is triggered by the hybrid structure of intermediate I possessing a stable geometry only in the carbene form and dictated by the mechanism of 1,2-migration. ${ }^{[42]}$ However, we observed that isomerisation of a mixture of Z/E 3-oxoindolines could be easily achieved in solution and in the presence of catalytic amount of iodine. Thus, performing the reaction as described in scheme 28 and treating the reaction mixture with iodine at the end of the reaction, we were able to obtain the exclusive formation of the $Z$ isomer, scheme 29. 


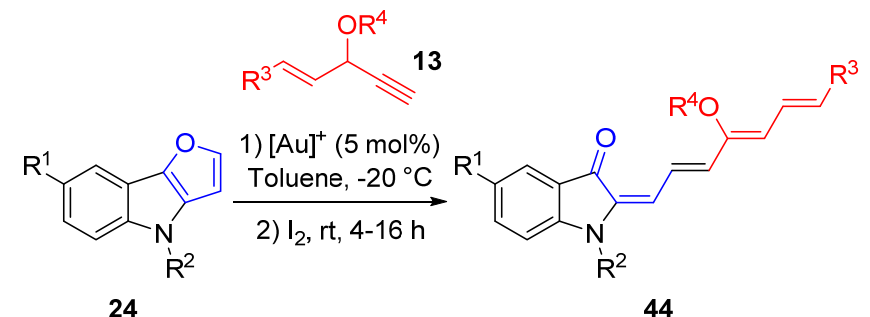

$$
\begin{aligned}
& \mathrm{R}^{1}=\mathrm{H}, \mathrm{F}, \mathrm{MeO} \\
& \mathrm{R}^{2}=\mathrm{CO}_{2} \mathrm{Et}, \mathrm{Boc}, \mathrm{Me} \\
& \mathrm{R}^{3}=\mathrm{Ar} \\
& \mathrm{R}^{4}=\mathrm{Piv} \\
& {[\mathrm{Au}]^{+}=\left[\mathrm{Au}(\text { JohnPhos }) \mathrm{SbF}_{6}(\mathrm{MeCN})\right]}
\end{aligned}
$$

Scheme 29. Scope of the reaction between 24 and 13 under optimized conditions.

At this stage of our investigation, we did not search for the reaction conditions enabling for the synthesis of the tetracyclic compound 45 that probably arises from a [4+3] cyclisation pathway in which the gold carbene acts as an oxyallyl cation. Moreover, the obtained compounds complement the already known classes of the 2-methyleneindolin-3-one ${ }^{[43]}$ (indigo derivatives) and 2-allylideneindolin-3one ${ }^{[44]}$ representing one of the few example of trienylidene derivatives. ${ }^{[45]}$ Finally, the synthesized 3-indolinones 44 show intense colouration (from yellow to purple) and have been characterised by UV measurements. Once again, as previously outlined for the reaction with allenamides, the reaction takes advantage of the ability of cationic gold $(I)$ catalysts to selectively promote the formation of gold-carbenes from propargyl esters and to promote the electrophilic addition/ring opening sequence with furoindoles demonstrating once again the usefulness of these catalysts in promoting complex cascade reactions under extremely mild reaction conditions.

\section{Conclusions}

As reported in the introduction, this minireview deals with a particular class of gold catalysed reactions involving both cyclization and cycloaddition or cascade reactions of indole derivatives for the synthesis of polycyclic and complex compounds. More specifically, the

\begin{tabular}{|c|c|c|c|c|c|c|}
\hline \multirow[t]{2}{*}{ indole } & \multicolumn{2}{|c|}{$\begin{array}{l}\text { allenamides } \\
\text { Gold(I) catalyst }\end{array}$} & \multicolumn{2}{|c|}{$\begin{array}{l}\text { allenylesters } \\
\text { Gold(I) catalyst }\end{array}$} & \multicolumn{2}{|c|}{$\begin{array}{l}\text { N-tosylallenamides } \\
\text { Gold(I) catalyst }\end{array}$} \\
\hline & $\begin{array}{c}\text { achiral } \\
\text { de } \%\end{array}$ & $\begin{array}{c}\text { chiral } \\
\text { ee } \%\end{array}$ & $\begin{array}{c}\text { achiral } \\
\text { de } \%\end{array}$ & $\begin{array}{c}\text { chiral } \\
\text { ee } \%\end{array}$ & $\begin{array}{c}\text { achiral } \\
\text { de } \%\end{array}$ & $\begin{array}{l}\text { chiral } \\
\text { ee\% }\end{array}$ \\
\hline 2-vinyl & $99 \%$ & - & $99 \%$ & $70 \%$ & $99 \%$ & - \\
\hline 3-vinyl & $99 \%$ & - & - & - & - & $\begin{array}{l}\text { E } 92 \% \\
\text { Z } 97 \%\end{array}$ \\
\hline $\begin{array}{l}\text { 2-vinyl- } \\
\text { 3-methyl }\end{array}$ & $99 \%$ & $92 \%$ & - & - & - & $60 \%$ \\
\hline $\begin{array}{l}\text { 3-vinyl- } \\
\text { 2-methyl }\end{array}$ & - & $\begin{array}{l}\text { E } 84 \% \\
\text { Z 98\% }\end{array}$ & - & - & - & - \\
\hline
\end{tabular}
minireview focuses on those reactions involving in the cyclisation process an external substituent of the indole moiety as described in scheme $1 \mathrm{~b}$. This minireview consists of two sections dedicated to the chemistry of vinylindoles and furoindoles, respectively. The chemistry of gold catalysed reactions of vinylindoles comprises essentially [4+2] cycloaddition reactions with allenes, preformed or generated in situ, for the synthesis of carbazoles, table 3.

Table 3. [4+2] cycloadditions of vinylindoles with allenes.

Excellent levels of diastereoselectivity at the carbazole ring and at the exocyclic double bond of the carbazole moiety have been achieved for 2-vinylindoles with all tested allenes. Whereas reactions developed in the presence of chiral catalysts are less established and are limited to 2-vinylindoles and allenylesters. Other classes of vinylindoles are less investigated, as reported in table 3 . These remarks are not intended to encourage new investigation just to fill in the table. However, several remarks could be done for example on the lack of enantioselective reactions. As outlined in recent outstanding reviews, ${ }^{[46]}$ the three main strategies adopted for the development of gold catalysed enantioselective reactions encompass the use of bimetallic atropoisomeric phosphine ligands, monodentate phosphoroamidite ligands and the use of achiral cationic catalysts coupled with chiral counteranions. The use of these 
catalysts allowed for the realization of enantioselective transformations mainly based on the activation of alkyne, allene and alkene substrates in inter and intramolecular reactions with nucleophiles for the synthesis of cyclic compounds. However, over the last years, new methodologies in the more general field of transition metal catalysis gained major attention. Inter alias, hybrid catalysts, such as metalloenzymes, realised by including an organometallic catalyst in a host (artificial)protein, find application for efficient enantioselective transformations. ${ }^{[4]}$ These catalysts can be roughly defined as hybrid catalyst competently combining the catalytic activity of transition metals with the ability of the enzymes to create the functional chiral environment through covalent, dative or supramolecular bonds. Besides, metallo-peptides find applications in the same field with the advantage that peptides can be conveniently prepared via automated methodologies. ${ }^{[48]}$ Moreover, application of different type of nanostructures underwent incredible expansion over the last years including in catalysis. ${ }^{[49]}$ The most developed materials include chiral nanostructures mainly organised in nanotube, nanocage and micelles and based on the assembly of small and medium sized molecules. It is worth to mention that, apart from gold( 0$)$ nanoparticles, gold metal salts has been little or no included in these studies. The authors suggest referring to the cited specialised literature for deepening. Aside from the study of new catalysts, vinyl indoles deserve attention also in reactions different from classical [4+2] pathways. For example, the achievement of [4+1] cycloadditions could give rise to new carbocyclic and heterocyclic systems. Formal [4+1] gold(I) catalysed reactions has been reported in the literature. ${ }^{[50]}$ The one carbon unit is mainly provided by gold carbenes, however dienes itself has been never used as four carbons partner. Finally, higher order cycloadditions, such as [4+3] cycloadditions, has been recently described using gold-activated oxy- and aminoallyl cations as three carbons component. ${ }^{[12]}$ This chemistry could furnish the basis for the future development of the chemistry of vinylindoles.

In the second section of this minireview we reported our most recent achievements in the field of gold catalysis. In these works we employed $4 \mathrm{H}$-furo[3,2-b]indoles as substrates, a class of fused heterocycles that has been never explored in the field of gold catalysis. These substrates comprise a $4 \pi$-system similar to that present in the vinylindole structure but merged in a furan system. In the first study, $4 H$-furo[3,2-b]indoles were reacted with gold-activated allenes affording 2-spiro-3-oxindoles. Thus, 4H-furo[3,2-b]indoles undergo addition of the electrophilic species followed by a ring opening/ ring closing event. The first two steps have been reported also for simple furans for the synthesis of unsaturated carbonyl compounds. In the second study, in the presence of gold carbenes, generated in situ from properly substituted propargylic esters, 2-methylene-3-oxoindoles could be generated through the furan ring rearrangement. However, whereas in the first example only the $\mathrm{C} 2$ position of the reacting furoindole is involved in the first step of the reaction, in the second example, both $\mathrm{C} 2$ and $\mathrm{C} 3$ of the furoindole are involved in the reaction. In both cases, the high levels of selectivity and the mild reaction conditions employed give reason to believe that further expansion of this chemistry can be easily achieved probably by modulation of the reactivity of the $4 \mathrm{H}$-furo[3,2-b]indoles and by the accurate choice of electrophilic partners. In particular, as already established, substituents at the nitrogen atom induce a profound variation on the electronic properties of the indole moiety and this peculiarity can be exploited for the design of new transformations. We would consider, for example, the involvement of the furan moiety in cycloaddition reaction, in particular [4+3] cycloadditions not yet described for fused furan derivatives.

A final remark is devoted to the reaction mechanisms of all these transformations involving allenes. Most cyclisation steps involve intermediates containing a $\mathrm{N}-\mathrm{C}=\mathrm{C}-[\mathrm{Au}]$ motif from which the cyclisation occurs, see schemes $7,9,12,15$, and 26 . The ring closure can be explained thru diverse mechanisms, scheme 30.

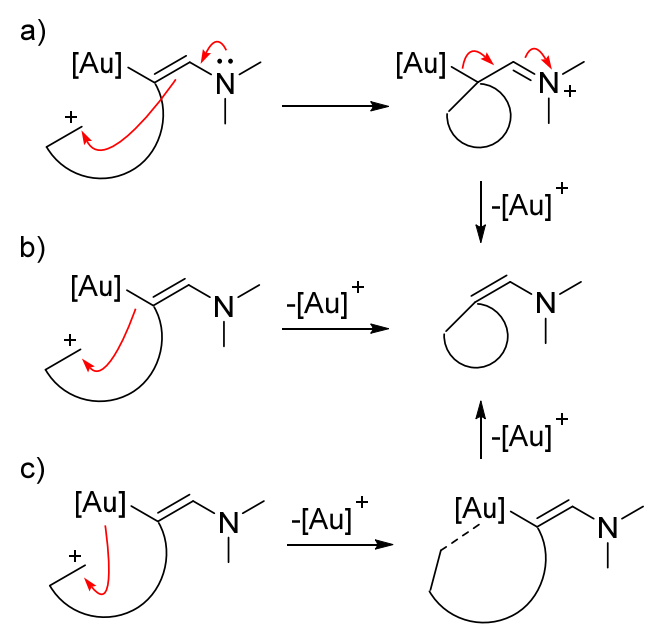

Scheme 30. Plausible cyclisation mode in vinyl-gold intermediates.

Scheme 30a reports a nitrogen assisted ring closure followed by cationic gold(I) elimination. In scheme 30b a heterolytic fragmentation of the $[\mathrm{Au}]-\mathrm{C}$ bond delivers the cyclisation product. Finally, in scheme $30 \mathrm{c}$ the cyclisation step is assisted by gold via an electrostatic interaction with the electrophilic moiety, resulting in a pseudo-metallacyclic intermediate from which elimination of gold(I) affords the final product. Several computational studies support the mechanisms reported in scheme $30 \mathrm{~b}^{[26]}$ and $30 \mathrm{c} .{ }^{[12,40]}$ Moreover, both mechanisms better explain the stereoselectivity observed for the exocyclic double bond in the final products. However, when loss of selectivity is observed, for example when $\mathrm{N}$-tosylallenamides are employed, an intermediate like that reported in scheme 30 a can not be excluded. 


\section{Acknowledgments}

We thank the MIUR-Italy (Ph.D. fellowship to E. B.) for financial support.

Keywords: gold catalysis $1 \cdot$ indoles $2 \cdot$ allenes $3 \cdot$ gold carbenes $4 \cdot$ cycloadditions 5

[1] (a) M. Bandini, A. Eichholzer, Angew. Chem. Int. Ed. 2009, 48, 9608-9644; (b) J.-B. Chen, Y.-X. Jia, Org. Biomol. Chem. 2017, 15, 3550-3567; (c) V. Pirovano, Eur. J. Org. Chem. 2018, 1925-1945.

[2] Selected recent reviews, indole chemistry: (a) E. Rossi, G. Abbiati, V. Pirovano, Eur. J. Org. Chem. 2017, 4512-4529; (b) B. M. Griffiths, J. D. Burl, X. Wang, Synlett 2016, 27, 2039-2042; (c) E. Manoni, A. De Nisi, M. Bandini, Pure Appl. Chem. 2016, 88, 207-214; (d) P. M. Barbour, L. J. Marholz, L. Chang, W. Xu, X. Wang, Chem. Lett. 2014, 43, 572-578; (e) G. Abbiati, F. Marinelli, E. Rossi, A. Arcadi, Isr. J. Chem. 2013, 53, 856-868; (f) G. Cera, M. Chiarucci, M. Bandini, Pure Appl. Chem. 2012, 84, 1673-1684; (g) C. C. J. Loh, D. Enders, Angew. Chem., Int. Ed. 2012, 51, 46-48; selected recent reviews, gold chemistry: (h) J. An, M. Bandini, Chimia 2018, 72, 610-613; (i) S. Shin, Top. Curr. Chem. 2015, 357, 25-62; (j) B. Alcaide, P. Almendros, Acc. Chem. Res. 2014, 47, 939-952; (k) H.-S. Yeom, S. Shin, Acc. Chem. Res. 2014, 47, 966-977; (I) A. S. K. Hashmi in Comprehensive Chirality, (Eds.: E. M. Carreira, H. Yamamoto), Elsevier, Amsterdam, 2012, pp. 685-737.

[3] (a) G. Abbiati, V. Canevari, D. Facoetti, E. Rossi, Eur. J. Org. Chem. 2007, 517-525; (b) G. Abbiati, M. Dell'Acqua, D. Facoetti, V. Pirovano, M. Giordano, E. Rossi, Synlett 2012, 23, 2913-2918; (c) V. Pirovano, M. Dell'Acqua, D. Facoetti, S. Rizzato, G. Abbiati, E. Rossi, Eur. J. Org. Chem. 2013, $6267-6279$.

[4] (a) Y. Yamamoto, J. Org. Chem. 2007, 72, 7817-7831; (b) A. D. Melhado, G. W. Amarante, Z. J. Wang, M. Luparia, F. D. Toste, J. Am. Chem. Soc. 2011, 133, 3517-3527; (c) A. D. Melhado, M. Luparia, F. D. Toste, J. Am. Chem. Soc. 2007, 129, 12638-12639; (d) M. Martín-Rodríguez, C. Nájera, J. M. Sansano, F.-L. Wu, Tetrahedron: Asymmetry 2010, 21, 1184-1186.

[5] F. López, J. L. Mascareñas, Beilstein J. Org. Chem. 2011, 7, 1075-1094

[6] S. Reymond, J. Cossy, Chem. Rev. 2008, 108, 5359-5406.

[7] Review: (a) M. Álvarez-Corral, M. Muñoz-Dorado, I. Rodríguez-García, Chem. Rev. 2008, 108, 3174-3198; selected examples: (b) H. Mandai, K. Mandai, M. L. Snapper, A. H. Hoveyda, J. Am. Chem. Soc. 2008, 130, 17961-17969; (c) J. M. Fernández-García, M. Á. Fernández-Rodríguez, E. Aguilar, Org. Lett. 2011, 13, 5172-5175; (d) N. H. Krishna, A. P. Saraswati, M. Sathish, N. Shankaraiaha, A. Kamal, Chem. Commun. 2016, 52, 4581-4584.

[8] A. S. K. Hashmi, L. Schwarz, J.-H. Choi, T. M. Frost, Angew. Chem., Int. Ed. 20008, 39, 2285-2288; (b) A. S. K. Hashmi, T. M. Frost, J. W. Bats, J. Am. Chem. Soc. 2000, 122, 11553-11554.

[9] V. Pirovano, L. Decataldo, E. Rossi, R. Vicente, Chem. Commun. 2013, 49, 3594-3596.

[10] E. Rossi, G. Abbiati, V. Canevari, G. Celentano, E. Magri, Synthesis 2006, 299-304.

[11] The notation [4+2], [2+2], [4+3] etc. refers to the number of atom involved and not to the electron count of the cycloaddition. Notation in round brackets would me more appropriate in some cases, however, as in the majority of the paper cited in this review, the square brackets are used, we decided to use square brackets too.

[12] (a) J. L. Mascareñas, I. Varela, F. López, Acc. Chem. Res. 2019, 52, 465-479; (b) M. P. Munoz, C. Hurtado-Rodrigo in Chemistry of Organogold Compounds, (Eds.: Z. Rappoport, J. F. Liebman, I. Marek), John Wiley \& Sons Ltd., Chichester, 2014, pp. 567-630; (c) W. Yang, A. S. K. Hashmi, Chem. Soc. Rev. 2014, 43, 2941-2955; (d) B. Alcaide, P. Almendros, Acc. Chem. Res. 2014, 47, 939-952.

[13] (a) P. Mauleón, R. M. Zeldin, A. Z. González, F. D. Toste, J. Am. Chem. Soc. 2009, 131, 6348-6349; (b) B. Trillo, F. López, S. Montserrat, G. Ujaque, L. Castedo, A. Lledós, J. L. Mascareñas, Chem. Eur. J. 2009, 15, 3336-3339; (c) B. Trillo, F. López, M. Gulías, L. Castedo, J. L. Mascareñas, Angew. Chem. Int. Ed. 2008, 47, 951-954; (d) H. Teller, S. Flügge, R. Goddard, A. Fürstner, Angew. Chem., Int. Ed. 2010, 49, 1949-1953; (e) I. Alonso, B. Trillo, F. López, S. Montserrat, G. Ujaque, L. Castedo, A. Lledós, J. L. Mascareñas, J. Am. Chem. Soc. 2009, 131, 13020-13030.

[14] G. Wang, Y. Zou, Z. Li, Q. Wang, A. Goeke, Adv. Synth. Catal. 2011, 353, 550-556.

[15] H. Faustino, F. López, L. Castedo, J. L. Mascareñas, Chem. Sci. 2011, 2, 633-637.

[16] C. Obradorsa, A. M. Echavarren, Chem. Commun. 2014, 50, 16-28.

[17] A. S. K. Hashmi, Angew. Chem., Int. Ed. 2010, 49, 5232-5241.

[18] V. Pirovano, E. Arpini, M. Dell'Acqua, R. Vicente, G. Abbiati, E. Rossi, Adv. Synth. Catal. 2016, 358, 403-409.

[19] (a) P. Maulron, Pablo, F. D. Toste, in Modern Gold Catalyzed Synthesis, (Eds.: A. S. K. Hashmi, F. D. Toste), Wiley-VCH Verlag GmbH \& Co. KGaA, Weinheim, 2012, pp. 75-134; (b) Y. Zhu, L. Sun, P. Lu, Y. Wang, ACS Catal. 2014, 4, 1911-1925.

[20] (a) J. Rodriguez, D. Bourissou, Angew. Chem. Int. Ed. 2018, 57, 386-388; (b) Y. Li, W. Li, J. Zhang, Chem. Eur. J. 2017, 23, 467-512; (c) S. M. Inamdar, A. Konala, N. T. Patil, Chem. Commun. 2014, 50, 15124-15135; (d) C. Najera, J. M. Sansano, J. Organomet. Chem. 2014, 771, 78-92; (e) P. Gu, Q. Xu, M. Shi, Tetrahedron Lett. 2014, 55, 577-584; (f) G. Cera, M. Bandini, Isr. J. Chem. 2013, 53, 848-855; (g) M. Barbazanges, L. Fensterbank, ChemCatChem 2012, 4, 1065-1066; (h) A. Pradal, P. Y. Toullec, V. Michelet, Synthesis 2011, 1501-1514; (i) Y.-N. Gao, F.-C. Shi, Q. Xu, M. Shi, Chem. Eur. J. 2016, 22, 68036807; (j) Y.-M. Wang, A. D. Lackner, F. D. Toste, Acc. Chem. Res. 2014, 47, 889-901.

[21] J. Francos, F. Grande-Carmona, H. Faustino, J. Iglesias-Sigüenza, E. Díez, I. Alonso, R. Fernández, J. M. Lassaletta, F. López, J. L. Mascareñas, J. Am. Chem. Soc. 2012, 134, 14322-14325.

[22] X. Bugaut, F. Glorius, Chem. Soc. Rev. 2012, 41, 3511-3522.

[23] M. He, J. R. Struble, J. W. Bode, J. Am. Chem. Soc. 2006, 128, 8418-8420.

[24] J. Iglesias-Sigüenza, A. Ros, E. Díez, M. Alcarazo, E. Álvarez, R. Fernández, J. M. Lassaletta, Dalton Trans. 2009, 7113-7120.

[25] M. Jia, M. Monari, Q.-Q. Yang, M. Bandini, Chem. Commun. 2015, 51, 2320-2323.

[26] R. Ocello, A. De Nisi, M. Jia, Q.-Q. Yang, M. Monari, P. Giacinto, A. Bottoni, G. P. Miscione, M. Bandini, Chem. Eur. J. 2015, 21 , $18445-18453$.

[27] V. Pirovano, M. Borri, G. Abbiati, S. Rizzato, E. Rossi, Adv. Synth. Catal. 2017, 359, 1912-1918.

[28] Y. Wang, P. Zhang, Y. Liu, F. Xia, J. Zhang, Chem. Sci. 2015, 6, 5564-5570.

[29] H. Hu, Y. Wang, D. Qian, Z.-M. Zhang, L. Liu, J. Zhang, Org. Chem. Front. 2016, 3, 759-763.

[30] (a) S.-H. Zhuang, Y.-C. Lin, L.-C. Chou, M.-H. Hsu, H.-Y. Lin, C.-H. Huang, J.-C. Lien, S.-C. Kuo, L.-J. Huang, Eur. J. Med. Chem. 2013, 66, 466-479; (b) Y. Kawashima, F. Amanuma, M. Sato, S. Okuyama, Y. Nakashima, K. Sota, K., I. Moroguchi, J. Med. Chem. 1986, 29, $2284-2290$.

[31] (a) A. Tanaka, K. Yakushiyin, S. Yoshina, J. Heterocycl. Chem. 1977, 14, 975-979; (b) A. Tanaka, K. Yakushiyin, S. Yoshina, J. Heterocycl. Chem. 1978, 15, 123-125; (c) A. Tanaka, K. Yakushiyin, S. Yoshina, J. Heterocycl. Chem. 1979, 16, 785-788; (d) M. Pudlo, D. Csanyi, F. Moreau, G. Hajos, Z. Riedl, J. Sapi, Tetrahedron 2007, 63, 10320-10329.

[32] Reviews: (a) S. Bur, A. Padwa in Methods and Applications of Cycloaddition Reactions in Organic Syntheses, (Ed.: N. Nishiwaki), John Wiley \& Sons, Inc., Hoboken, 2014, pp. 355-406; (b) A. Padwa, A. C. Flick, Adv. Heterocycl. Chem. 2013, 110, 1-41; selected example: (c) A. V. Lofstrand, K. C. Mclntosh, Y. A. Almehmadi, F. G. West, Org. Lett. 2019, 21, 6231-6234. 
[33] Reviews: (a) M. Harmata, Adv. Synth. Catal. 2006, 348, 2297-2306; (b) M. Harmata, Chem. Commun. 2010, 46, 8886-8903; (c) M. Harmata, Chem. Commun. 2010, 46, 8904-8922; (d) A. G. Lohse, R. P. Hsung, Chem. Eur. J. 2011, 17, 3812-3822; (e) I. Fernández, J. L. Mascareñas, Org. Biomol. Chem. 2012, 10, 699-704; selected example: (f) M. Topinka, K. Zawatzky, C. L. Barnes, C. J. Welch, M. Harmata, Org. Lett. 2017, 19, 4106-4109.

[34] (a) S. M. M. Lopes, M. S. C. Henriques, J. A. Paixão, T. M. V. D. Pinho e Melo, Eur. J. Org. Chem. 2015, 6146-6151; (b) R. Huang, X. Chang, J. Li, C.-J. Wang, J. Am. Chem. Soc. 2016, 138, 3998-4001; (c) A. J. S. Alves, S. M. M. Lopes, M. S. C. Henriques, J. A. Paixão, T. M. V. D. Pinho e Melo, Eur. J. Org. Chem. 2017, 4011-4025.

[35] Y. Chen, G. Li, Y. Liu, Adv. Synth. Catal. 2011, 353, 392-400.

[36] Reviews: (a) A. V. Butin, V. T. Abaev, T. A. Stroganova, A. V. Gutnov, Targets Heterocycl. Syst. 2001, 5, 131-168; (b) I. V. Trushkov, M. G. Uchuskin, A. V. Butin, Eur. J. Org. Chem. 2015, 2999-3016.

[37] L. El Kaïm, L. Grimaud, S. Wagschal, Chem. Commun., 2011, 47, 1887-1889.

[38] D. Leboeuf, M. Gaydou, Y. Wanga and A. M. Echavarren, Org. Chem. Front. 2014, 1, 759-764.

[39] V. Pirovano, E. Brambilla, S. Rizzato, G. Abbiati, M. Bozzi, E. Rossi, J. Org. Chem. 2019, 84, 5150-5166.

[40] A. Z. González, D. Benitez, E. Tkatchouk, W. A. Goddard, F. D. Toste, J. Am. Chem. Soc. 2011, 133, 5500-5507.

[41] E. Brambilla, V. Pirovano, M. Giannangeli, G. Abbiati, A. Caselli, E. Rossi, Org. Chem. Front. 2019, 6, 3078-3084.

[42] W. Rao, Sally, S. N. Berry and P. W. H. Chan, Chem. Eur. J. 2014, 20, 13174-13180.

[43] C. Petermayer, S. Thumser, F. Kink, P. Mayer, H. Dube, J. Am. Chem. Soc. 2017, 139, 15060-15067 and references cited therein.

[44] (a) A. D. Dubonosov, L. M. Sitkina, V. A. Bren, A. Y. Bushkov, V. I. Minkin, Chem Heterocycl Compd 1984, 20, 951-957; (b) C. Guo, M. Schedler, C. G. Daniliuc, F. Glorius, Angew. Chem. Int. Ed. 2014, 53, 10232-10236.

[45] (a) W. Flitsch, R. A. Jones, M. Hohenhorst Tetrahedron Lett., 1987, 28, 4397-4398; (b) W. Flitsch, and M. Hohenhorst, Liebigs Annalen der Chemie, 1990, 449-452.

[46] (a) Z. Weiwei, F. D. Toste, Chem. Soc. Rev. 2016, 45, 4567-4589; (b) S. M. Inamdar, A. Konala, N. T. Patil, Chem. Commun. $2014,50,15124-15135$.

[47] (a) J. C. Lewis, Acc. Chem. Res. 2019, 52, 576-584; (b) M. Vaquero, L. Rovira, A. Vidal-Ferran, Chem. Commun. 2016, 52, 11038-11051; (c) A. J. Gellman, W. T. Tysoe, F. Zaera, Catal. Lett. 2015, 145, 220-232.

[48] G. Roelfes, ChemCatChem 2011, 3, 647-648.

[49] (a) J. M. Fernandez-Garcia, P. J. Evans, S. Filippone, M. A. Herranz, N. Martin, Acc. Chem. Res. 2019, 52, 1565-1574; (b) H. Jiang, L. Zhang, M. Liu, ChemNanoMat 2018, 4, 720-729; (c) J. Govan, Y. K. Gun'ko, Y. K. Nanoscience 2016, 3, 1-30; (d) J. Jiang, G. Ouyang, L. Zhang, M. Liu, Chem. Eur. J. 2017, 23, 9439-9450; (e) T. Yasukawa, H. Miyamura, S. Kobayashi, ACS Catalysis 2016, 6, 7979-7988.

[50] (a) L.-y. Zhou, X.-m. Guo, Z.-c. Zhang, J. Li, J. Organomet. Chem. 2019, 897, 70-79; (b) A. M. Sanjuan, C. Virumbrales, P. Garcia-Garcia, M. A. FernandezRodriguez, R. Sanz, Org. Lett. 2016, 18, 1072-1075; (c) J. Wang, X. Yao, T. Wang, J. Han, J. Zhang, X. Zhang, P. Wang, Z. Zhang, Org. Lett. 2015, 17, 5124-5127; (d) Y. Wang, M. E. Muratore, Z. Rong, A. M. Echavarren, Angew. Chem. Int. Ed. 2014, 53, 14022-14026; (e) R. B. Dateer, K. Pati, R.-S. Liu, Chem. Commun. 2012, 48, 7200-7202. 